\title{
Quantitative analysis of NRF2 pathway reveals key elements of the regulatory circuits underlying antioxidant response and proliferation of ovarian cancer cells
}

Hilal S. Khalil, Alexey Goltsov, Simon P. Langdon, David J. Harrison, James Bown, Yusuf Deeni

This is the accepted manuscript (C) 2015, Elsevier Licensed under the Creative Commons Attribution-NonCommercial-NoDerivatives 4.0 International (CC BY-NC-ND 4.0) http://creativecommons.org/licenses/by-nc-nd/4.0/

The published article is available from doi:

http://dx.doi.org/10.1016/j.jbiotec.2014.09.027 
Quantitative analysis of NRF2 pathway reveals key elements of the regulatory circuits underlying antioxidant response and proliferation of ovarian cancer cells

Hilal S. Khali1 ${ }^{1, *}$, Alexey Goltsov ${ }^{1, *}$, Simon P. Langdon ${ }^{2}$, David J. Harrison ${ }^{3}$, James Bown ${ }^{1}$, Yusuf Deeni ${ }^{1, \S}$

1 Scottish Informatics, Mathematics, Biology and Statistics Centre (SIMBIOS), University of Abertay Dundee, Dundee, DD1 1HG, United Kingdom; E-Mails:

H.Khalil@abertay.ac.uk (H.K.); a.goltsov@abertay.ac.uk (AG); J.Bown@,abertay.ac.uk (J.B.)

2 Division of Pathology, Institute of Genetics and Molecular Medicine, University of Edinburgh, Western General Hospital, Edinburgh, EH4 2XU, United Kingdom; E-Mail: Simon.Langdon@ed.ac.uk

3 School of Medicine, University of St Andrews, St Andrews, KY16 9TF, United Kingdom; E-Mail: david.harrison@st-andrews.ac.uk

* Contributed equally and should be regarded as joint first authors

${ }^{\S}$ Author to whom correspondence should be addressed; E-Mail: y.deeni@abertay.ac.uk (Y.D.); Tel.: +44(0)1382-308672 


\section{Abstract}

Cells are constantly exposed to Reactive Oxygen Species (ROS) produced both endogenously to meet physiological requirements and from exogenous sources. While endogenous ROS are considered as important signaling molecules, high uncontrollable ROS are detrimental. It is unclear how cells can achieve a balance between maintaining physiological redox homeostasis and robustly activate the antioxidant system to remove exogenous ROS. We have utilized a Systems Biology approach to understand how this robust adaptive system fulfills homeostatic requirements of maintaining steady-state ROS and growth rate, while undergoing rapid readjustment under challenged conditions. Using a panel of human ovarian and normal cell lines, we experimentally quantified and established interrelationships between key elements of ROS homeostasis. The basal levels of NRF2 and KEAP1 were cell line specific and maintained in tight correlation with their growth rates and ROS. Furthermore, perturbation of this balance triggered cell specific kinetics of NRF2 nuclearcytoplasmic relocalisation and sequestration of exogenous ROS. Our experimental data were employed to parameterize a mathematical model of the NRF2 pathway that elucidated key response mechanisms of redox regulation and showed that the dynamics of $\mathrm{NRF} 2-\mathrm{H}_{2} \mathrm{O}_{2}$ regulation defines a relationship between half-life, total and nuclear NRF2 level and endogenous $\mathrm{H}_{2} \mathrm{O}_{2}$ that is cell line specific.

Key words: Proliferation, ROS, Oxidative Stress, NRF2 localisation, Mathematical Modelling 


\section{Introduction}

Proliferation is an intrinsic component of cellular growth and development that is tightly coupled to the state of a cell, and especially metabolism, and its environmental context (Fritz et al., 2010). This mix of internal and external conditions often results in the generation of both endogenous and exogenous free radicals in the form of reactive oxygen species (ROS). ROS are highly reactive molecules, often in the form of hydroxyl radical $\left(\mathrm{OH}^{-}\right)$, hydrogen peroxide $\left(\mathrm{H}_{2} \mathrm{O}_{2}\right)$ and superoxide $\left(\mathrm{O}_{2}^{-}\right)$as well as reactive nitrogen species. ROS can cause damage to cellular macromolecules such as DNA, proteins and lipids when not sequestered and managed (Brieger et al., 2012). Thus ROS exert oxidative stress and create redox perturbations in the cell that manifest through antioxidant defences until the restoration of redox homeostasis.

Cells have developed and evolved coordinated mechanisms of sensing and signalling to respond to, and even intrinsically and extrinsically tolerate and adapt to ROS (Hamanaka et al., 2010; Martin et al., 2002). This is because low, graded and tolerable levels of ROS are key determinants and modulators of intracellular signalling pathways that govern and determine cellular proliferation in particular, and also differentiation, migration, developmental progression (from stemness to adulthood) and lifespan (D'Autréaux et al., 2007; Holmström et al., 2014; Martin et al., 2002). Thus ROS have acquired the status of second messengers in signal transduction pathways (Finkel, 2011; Rigoulet et al., 2011). In contrast, high levels of ROS are difficult to control and can lead to cellular accumulation of mutations and the acceleration of disease, ageing and death (Brieger et al., 2012). Biochemical strategies to curb ROS can be broadly grouped into non-enzymatic (low 
molecular weight) scavengers, such as glutathione (GSH), coenzyme Q, and lipoic acid, and enzymatic antioxidant defense systems that include superoxide dismutases, catalases, peroxidases, thioredoxins, peroxiredoxins and reductases (Nordberg et al., 2001; Sies, 1997). The strategies extend to connect to several other oscillatory systems and pathways that coordinate and transduce signals to effector molecules or cellular compartments (Circu et al., 2010). Overall, levels of one antioxidant system cause compensatory alterations in the levels of the others, together with other associated pathways, to restore redox homeostasis that transduce into a multitude of pathways leading to different physiological consequences (Valko et al., 2007).

The extensive and complex manner in which the redox network and its interconnections influence cellular proliferation is challenging to understand. Importantly, extensive research over the last decade has systematically unravelled the details of a gene regulatory network that centres on a specific trans-acting regulatory factor known as nuclear erythroid 2-related factor, NRF2 (Niture et al., 2013). NRF2 drives both the basal and inducible transcription of genes associated with redox homeostasis and cytoprotection, as well as other signal transduction pathways (Jaiswal, 2004). This is achieved by heterodimerising with small MAF proteins and binding to some cis-acting factors called Antioxidant Response Elements (AREs) or electrophile response elements (EpREs) within the promoters of these genes (Kimura et al., 2007; Li et al., 2008). Under normoxic conditions, little free NRF2 is available in the cytoplasm and for translocation to the nucleus to drive the basal transcription of target genes. Most of the remaining cytosolic NRF2 is anchored by KEAP1, a cytoplasmic NRF2-binding adaptor and sensor protein, which tethers NRF2 for association with the Cul3based E3 ubiquitin ligase to promote its degradation by the $26 \mathrm{~S}$ proteasome (Kaspar et al., 2009). 
Under oxidative stress or in the presence of NRF2 inducers, a number of cysteine residues of KEAP1 become oxidised to cause conformational changes in the KEAP1 structure. This allows NRF2 to escape from being targeted by the $26 \mathrm{~S}$ proteasomal degradation machinery and to accumulate in the nucleus to further induce the transactivation of ARE-containing genes in order to restore redox homeostasis (Kobayashi et al., 2005). Biochemical and structural analyses have revealed the existence of a cherry-bob structure in which one molecule of NRF2 associates with two molecules of KEAP1 via two binding sites (hinge and latch model) within the Neh2 domain of NRF2. This model is supported and extended by the recent proposed cyclic sequential attachment and regeneration model of KEAP1-mediated degradation of NRF2 (Baird et al., 2013; Ogura et al., 2010; Tong et al., 2006). Several other mechanisms of perturbing and controlling the cellular NRF2-KEAP1 dynamics in relation to ROS also exist and are supported by both in vitro and in vivo models (Cullinan et al., 2004, Furukawa et al., 2005, Yamamoto et al., 2008). Importantly here, NRF2-KEAP1 mutations and other perturbations leading to permanent constitutive adaptive activation of the NRF2 pathway are increasingly observed in cancers (Hayes et al., 2009, Shibata et al., 2008, Ohta et al., 2008) and other diseases (Satoh et al., 2009; Wakabayashi et al., 2003). It is well known that several therapeutic strategies, for example anticancer radiotherapy and chemotherapy, largely depend on ROS manipulation to induce cytotoxicity. More recently, there is a growing body of evidence implicating NRF2 and ROS in the promotion of cellular proliferation and therapeutic resistance in cancer cells (Homma et al., 2009, Hu et al., 2005; Lister et al., 2011; Reddy et al., 2007; Ruiz-Ginés et al., 2000). 
A key step in understanding the effect of ROS on cell behaviour and the consequence of its alteration to meet particular physiological requirements is the identification and characterisation of signalling pathways that detect and respond to ROS and subsequently initiate appropriate responses. Thus cellular tolerance, selectivity and ROS manipulation strategies to impact the fate of both normal and diseased cells may depend on their individual, heterogeneous net redox status and its potential to restore its balance upon perturbation. It is practically difficult to measure precisely all forms of ROS within and around the cellular microenvironment and compartments, as well as assessing the redox protective and repair potential of cells over time. Previous work has investigated a range of different aspects of the antioxidant defence systems to model cellular proliferation and redox homeostasis either in general or surrounding the NRF2 pathway (Aon et al., 2010; Gauthier et al., 2013; Hamon et al., 2014; Selivanov et al., 2011; Taylor et al., 2008). It is clear that the cellular redox potential and the associated dynamics of changing ROS levels in various cellular compartments and organelles are intricately interconnected with the operation of the redox homeostatic regulatory network. This regulatory network comprises ROS itself as well as transcriptional, translational and post-translational elements of regulation. All these elements converge on a NRF2-centred adaptive system, which thus presents itself as an appealing and measurable system to model ROS production and sequestration and make predictions. The NRF2-centred system serves as a key redox interconnectivity node and interface between ROS and the regulation of functioning in a broad spectrum of cellular physiological and pathological processes including proliferation.

In line with this NRF2 focus, we have profiled the proliferation of normal epithelial keratinocytes (HaCaT) and a panel of ovarian (OVCAR3, OVCAR4, PEO1, PEO4, PEO6 and SKOV3) cancer cell lines under both basal and perturbed redox status. We have 
quantified and evaluated the dynamics of ROS production and sequestration capacity, as well as the levels, stability and localisation of NRF2 and the basal expression of KEAP1 in these cell lines. We have used our experimental data, in conjunction with experimental data regarding oxidative stress responses and the NRF2-KEAP1 pathway by others (Malhotra et al 2010;) to mathematically model oxidative stress. The model accounts for the major components that interdependently feed into and out of the NRF2-centred network to sequester ROS. The model integrates NRF2-KEAP1 signalling in the cytoplasm and genetic regulation of NRF2-dependent antioxidative enzymes and involves negative feedback between these two control systems. Through this minimal integrative model of cellular oxidative stress responses due to ROS we explore the link between the ROS scavenging system and our existing knowledge of the NRF2-centred adaptive system.

\section{Materials and Methods}

\subsection{Experimental Methods}

\subsubsection{Cell lines, culture conditions and treatments}


Immortalised human keratinocytes $(\mathrm{HaCaT})$ were maintained in DMEM while human ovarian cancer cell lines PEO1, PEO4, PEO6, SKOV3, OVCAR3 and OVCAR4 were maintained in RPMI 1640 (Gibco® Invitrogen, UK) both media supplemented with $10 \%$ foetal bovine serum (FBS), $2 \mathrm{mM}$ glutamine, $1 \mathrm{mM}$ sodium pyruvate, $100 \mu \mathrm{g} / \mathrm{ml}$ streptomycin and $100 \mathrm{U} / \mathrm{ml}$ penicillin in an atmosphere of $5 \% \mathrm{CO}_{2}$. For reducing conditions, 100mM N-Acetyl Cysteine (Sigma-Aldrich) was prepared in deionised water and diluted to a final concentration of $10 \mathrm{mM}$ with media during treatments. For oxidative stress conditions, $30 \% \mathrm{H}_{2} \mathrm{O}_{2}$ (Sigma-Aldrich) was diluted in deionised water to prepare $10 \mathrm{mM}$ stock on the day of treatment and was further diluted in media to different concentrations depending upon type of experiments.

\subsubsection{ROS detection assays}

The $\mathrm{H}_{2} \mathrm{O}_{2}$ detection assay was performed using 10-acetyl-3,7-dihydroxyphenoxazine (Amplex ${ }^{\circledR}$ Red reagent, Invitrogen) following the manufacturer's protocol. Briefly, cells were seeded at a density of $5 \times 10^{3}$ cells/well in $50 \mu 1$ media without phenol red and were allowed to grow in opaque flat bottom 96-well tissue culture plates. On the day of assay, the Amplex ${ }^{\circledR}$ Red reagent was diluted in DMSO (Fisher Bioreagents) to obtain a stock concentration of $10 \mathrm{mM}$, while $10 \mathrm{U} / \mathrm{ml}$ of Horse Radish Peroxidase (HRP) was prepared in the provided $1 \mathrm{x}$ reaction buffer. At the time of $\mathrm{H}_{2} \mathrm{O}_{2}$ detection, a working stock of $100 \mu \mathrm{M}$ Amplex ${ }^{\circledR}$ Red and $0.2 \mathrm{U} / \mathrm{ml}$ of HRP was prepared in $50 \mu 1$ reaction buffer and added directly onto cells with media in each well of the 96-well plate. The plates were incubated for 30 minutes (min) at $37^{\circ} \mathrm{C}$ followed by taking readings using 96 -well fluorescent multi plate reader (MODULUS ${ }^{\mathrm{TM}}$, Promega) using excitation and emission spectra of 530/590nm. To 
estimate actual $\mathrm{H}_{2} \mathrm{O}_{2}$ levels from the signals obtained above, standard calibration curves for $\mathrm{H}_{2} \mathrm{O}_{2}$ were established by preparing serial dilutions of $20 \mu \mathrm{M} \mathrm{H}_{2} \mathrm{O}_{2}$ in $50 \mu \mathrm{l}$ volume each in a 96-well plate and adding $50 \mu 1$ of Amplex ${ }^{\circledR}$ Red/HRP reagent prepared as above and following the same protocol onwards for detection.

For the detection of $\mathrm{H}_{2} \mathrm{O}_{2}$ neutralisation/degradation kinetics for different cells, $\mathrm{H}_{2} \mathrm{O}_{2}$ reduction assay was designed. For this, $1 \times 10^{4}$ cells were seeded in a flat bottom 96 -well tissue culture plate in $100 \mu \mathrm{l}$ media. Next day, cells were washed with warm PBS and $50 \mu \mathrm{l}$ of new media (without phenol red) containing $5 \mu \mathrm{M} \mathrm{H}_{2} \mathrm{O}_{2}$ was added. At different time points after addition of $\mathrm{H}_{2} \mathrm{O}_{2}$, media from each well was transferred to a new opaque 96-well plate and $50 \mu \mathrm{l}$ of the Amplex ${ }^{\circledR}$ Red reagent prepared as above was added. The plate was incubated for $30 \mathrm{~min}$ at $37^{\circ} \mathrm{C}$ and readings were taken as above.

For total cellular ROS detection, CellROX ${ }^{\circledR}$ Green reagent (Invitrogen) was used. Briefly, 1× $10^{4}$ cells were seeded in opaque 96-well tissue plates and allowed to attach for $18 \mathrm{~h}$. At the time of assay, CellROX ${ }^{\circledR}$ Green reagent was transferred into each well containing cells and media to achieve $5 \mu \mathrm{M}$ concentration and allowed to incubate at $37^{\circ} \mathrm{C}$ for $30 \mathrm{~min}$. Following this, cells were washed thrice with PBS and immediately analysed for fluorescent signal in 96-well plate reader (Modulus template, Promega) using excitation and emission spectra of $485 / 520 \mathrm{~nm}$ or imaged with a Leica DMiRe2 electronic microscope under relevant channel.

\subsubsection{Total protein extraction, protein half-life and sub cellular fractionation}


For quantitative immunoblotting, cells were seeded in $60 \mathrm{~mm}$ tissue culture plates and grown until $70 \%$ confluent. At the time of protein harvest, cells were trypsinized (Gibco ${ }^{\circledR}$ Invitrogen), washed with PBS and counted using haemocytometer. Protein lysates were prepared from $1 \times 10^{6}$ cells using RIPA buffer (Pierce Biotech) supplemented with protease and phosphatase inhibitor cocktail (Pierce Biotech) and subjected to sonication of 2 cycles for $10 \mathrm{~s}$ at $50 \%$ pulse. The final mixture was shaken gently on ice for $15 \mathrm{~min}$ and the protein supernatant was obtained by centrifuging the lysates at $14,000 \mathrm{x}$ g for $15 \mathrm{~min}$. The proteins were quantified by Bradford assay (Sigma-Aldrich) using BSA as a standard and sample buffer (Nupage LDS, Invitrogen) was added to protein lysates, heated at $70^{\circ} \mathrm{C}$ for $20 \mathrm{~min}$ and stored at $-20^{\circ} \mathrm{C}$ until needed.

To study protein half-life, cells were seeded as above and once $70 \%$ confluent, were exposed to $50 \mu \mathrm{M}$ of protein synthesis inhibitor Cycloheximide (CHX) (Sigma-Aldrich). At different time points following $\mathrm{CHX}$ addition, cells were processed for immunoblotting as above.

To prepare nuclear and cytoplasmic fractions, cells were lysed in ice-cold hypotonic buffer (10 mM KCl, 0.1 mM EGTA, 0.1 mM EDTA, 10 mM HEPES pH 8, 1 mM DTT, 0.5 mM PMSF, $1 \mathrm{mg} / \mathrm{ml}$ aprotinin, $1 \mathrm{mg} / \mathrm{ml}$ leupeptin, $1 \mathrm{mg} / \mathrm{ml}$ pepstatin, $0.1 \mathrm{mM} \mathrm{Na3VO4),}$ centrifuged and the resulting supernatant (cytosolic fraction) was immediately analyzed or stored at $80^{\circ} \mathrm{C}$ until needed. To obtain nuclear fractions, the pellet was briefly washed thrice in ice-cold hypertonic buffer $(0.4 \mathrm{M} \mathrm{NaCl}, 1 \mathrm{mM}$ EGTA, $1 \mathrm{mM}$ EDTA, $20 \mathrm{mM}$ Hepes pH 8.0, $1 \mathrm{mM}$ DTT, $1 \mathrm{mM}$ PMSF, $1 \mathrm{mg} / \mathrm{ml}$ aprotinin, $1 \mathrm{mg} / \mathrm{ml}$ leupeptin, $1 \mathrm{mg} / \mathrm{ml}$ pepstatin, 0.1 $\mathrm{mM} \mathrm{Na3VO4),} \mathrm{followed} \mathrm{by} \mathrm{incubation} \mathrm{in} \mathrm{hypertonic} \mathrm{buffer} \mathrm{for} 30 \mathrm{~min}$ at $4^{\circ} \mathrm{C}$, and centrifugation $\left(13,000 \times \mathrm{g}, 5 \mathrm{~min}, 4^{\circ} \mathrm{C}\right)$. The supernatant (nuclear fraction) was immediately analyzed or stored at $80^{\circ} \mathrm{C}$ until used. Subsequently all protein extracts were quantified using 
the Bradford reagent as a before. Verification of the quality of sub-cellular fractions was done by performing immunoblotting using antibodies specific to nuclear and cytoplasmic marker proteins.

To determine absolute abundance of NRF2 and Keap-1 in cells, quantitative immunoblotting was performed and calibrated against known concentrations of respective recombinant proteins standards (Novus Biologicals). Briefly, serial dilutions of known concentrations of standard recombinant proteins were made using Nupage sample buffer (Invitrogen) and the proteins loaded onto SDS polyacrylamide gels for subsequent immunoblotting. The immunoblot signal detected for each of the known standard sample was used to establish a standard curve against which the concentration of immunoblot signal from test samples was calculated.

\subsubsection{Immunoblotting}

Prepared protein lysates as stated above were loaded into wells of 10\% SDS-polyacrylamide gels and subjected to electrophoresis at 200 Volts for $1-2 \mathrm{~h}$. Then proteins were transferred onto polyvinylidene difluoride membranes (GE Amersham) using the XCell SureLock MiniCell system (Invitrogen) at 50 Volts for $90 \mathrm{~min}$ and processed using a commercially available kit (WesternBreeze ${ }^{\mathrm{TM}}$ Chromogenic Immunodetection Kit, Invitrogen).

Non-specific reactivity was blocked by incubation with the blocking reagent supplied in the kit. Membranes were further treated by incubating with primary antibodies (Table 1) for $2 \mathrm{~h}$ at room temperature or overnight at $4^{\circ} \mathrm{C}$, followed by incubation for $30 \mathrm{~min}$ at room 
temperature with appropriate secondary anti mouse or anti rabbit antibody supplied in the kit. Bands were visualized with the BCIP/NBT based chromogenic substrate. For loading control, immunoblotting of the same lysates was performed using $\beta$-Actin antibody (Abcam Bioscience, UK).

\subsubsection{Proliferation assay}

The proliferation assay was performed by seeding $2 \times 10^{4}$ cells in triplicates in complete media per well in 24-well plate. This was considered as day 0. Following this, cells were trypsinized and counted from each well individually for 6 days and cell numbers were plotted against each day and analysed. For proliferation assay under reducing or oxidative stress conditions, cells were seeded (day 0) and maintained continuously in media containing 10 mM N-Acetyl Cysteine or $20 \mu \mathrm{M} \mathrm{H}_{2} \mathrm{O}_{2}$ (Sigma-Aldrich) and cells counted each day for 6 days.

\subsubsection{Immunocytochemistry/Immunolabelling}

For immunocytochemistry, exponentially growing cells were seeded at a density of $5 \times 10^{4}$ cells in complete media onto poly-L lysine (Sigma-Aldrich) coated cover slips placed in a 12well tissue culture plates. The next day, following relevant treatments, cells were washed three times with ice cold PBS, fixed in 3.5\% paraformaldehyde in a standard PBS at room temperature for $30 \mathrm{~min}$. Then cells were gently washed twice with $1 \mathrm{ml}$ of PBS, permeabilized with $0.3 \%$ triton $\mathrm{X}-100$ for $10 \mathrm{~min}$, and following three washed with PBS, blocked with $1 \%$ goat serum, $1 \%$ bovine serum albumin in PBS containing $0.05 \%$ Triton X- 
100 for $30 \mathrm{~min}$. Cells were then incubated with relevant primary antibody (Table 1) diluted in blocking solution for $1 \mathrm{~h}$, washed three times with $0.1 \%$ Triton X-100/PBS for $5 \mathrm{~min}$, and then incubated with Alexa Fluor 488/568- conjugated goat anti-rabbit or anti mouse antibodies (Invitrogen, UK) for $30 \mathrm{~min}$. Staining for F-Actin was performed by using Alexa fluor 568 conjugated Phalloidin (Invitrogen) according to manufacturers' instructions. After subsequent washing three times with the $0.1 \%$ Triton X-100/PBS for 5 min, cover slips with cells were mounted on slide using 4',6-Diamidino-2-Phenylindole, Dihydrochloride (DAPI)containing mounting reagent (Vectashield, Vector Laboratories) and imaged under relevant filters with a Leica DMiRe2 electronic microscope.

\subsubsection{Imaging and analysis}

Quantitative analysis of raw immunoblots was performed by capturing the images in high resolution TIFF format files using a charge-coupled-device camera (AxioCam MRc, Carl Zeiss) and subjected to Gelpro analysis software, version 3.1 (Gelpro Media Cybernetics) for densitometry. Fluorescence images of immunocytochemistry were collected under relevant excitation and emission filters depending on the fluorotype under Leica DMiRe2 electronic microscope equipped with iXonEM +897 EMCCD camera (ANDOR Technologies Ltd). Images were visualised using multidimensional microscopy software Andor Module iQ Core. Colocalization assays and fluorescence intensity measurements were performed and determined with software integral features supplied by Andor IQ core software. Data were generally expressed as mean \pm S.E.M. for individual sets of experiments. 


\subsubsection{Statistics}

All statistical analysis were performed using the software SPSS (IBM, version 22). Tests for normality of data were determined by Shapiro-Wilk and by Kolmogorov and Smirnov tests. For correlational analysis, either Pearsons or Spearmans two tailed or one-tailed tests were performed.

\subsection{Computational Methods}

The experimental data was analysed using a computational model describing the NFR2KEAP1-dependent mechanism of redox homeostasis regulation and NRF2 signalling. The model consists of three main subsystems NRF2 signalling (see scheme in Fig. 1): a) the cellular antioxidant system; b) KEAP1-dependent degradation/ ubiquitination of NRF2 in the cytoplasm; and c) gene regulation of the antioxidant system by NRF2. The model captures the following processes as distinct modules: 1) KEAP1-dependent degradation/ ubiquitination of NRF2 in the cytoplasm; 2) oxidation of KEAP1 by $\mathrm{H}_{2} \mathrm{O}_{2}$ resulting in the dissociation of the NRF2-KEAP1 complex and inhibition of NRF2 degradation; 3) diffusion of free NRF2 into the nucleus; 4) formation of the activation transcription factor NRF2-MAF heterodimer; 5) binding of NRF2-MAF to ARE sites; 6) translation of antioxidant enzymes including Trx, Tpx, and Gpx; 7) formation of the repression transcription factor MAF-MAF homodimer and its binding to ARE sites causing repression of NRF2-dependent gene transcription; 8) reduction of KEAP1 by Trx; 9) cellular production of $\mathrm{H}_{2} \mathrm{O}_{2}$ and its 
degradation by antioxidant enzymatic system; 10) diffusion of endogenous $\mathrm{H}_{2} \mathrm{O}_{2}$ through the cellular membrane; 11) catalysis of GSH from endogenous NAC.

The kinetic model of NRF2 signalling comprises of 16 ordinary differential equations provided in Supplement1. The model parameters were chosen based on experimental data available from literature and results of fitting of the model against our own experimental data (Tables S2 and S3 in Supplement I). In the model we have made the following assumptions. Oxidation of 2KEAP1-(SH) 2 leads to the formation of the KEAP1-SS-KEAP1 bond (Wakabayashi et al., 2004) and Trx1 reduces the KEAP1-SS-KEAP1 bond. The KEAP1 dimer binds to NRF2 molecules resulting in a 2:1 and 2:2 stoichiometry (Lo et al., 2006). NRF2 nuclear translocation is assumed to be free diffusion across nuclear membrane and KEAP1-independent. We ignored KEAP1-dependent NRF2 nuclear export (Sun et al., 2011).

The complex intracellular antioxidant system that degrades $\mathrm{H}_{2} \mathrm{O}_{2}$ was described phenomenologicaly in the model (Sokolovski et al., 2013) through the redox-balancing cascade reactions corresponding to key antioxidant enzymes, i.e. the thioredoxin peroxidase/ thioredoxin/ thioredoxin reductase (Tpx/Trx/TR) and glutathione peroxidase/ glutathione/ glutathione reductase (Gpx/GSS/GR) systems (see module 9 in Fig. 1). Instead of specific enzymes, we considered the following phenomenological enzymes: Px corresponding to peroxidase, Tpx and Gpx; PSH corresponding to GSH and Trx, protein containing thiol groups; and Red corresponding to reductases, with TR and GR reducing GSS and Trx. Kinetic parameters of these antioxidant enzymes in the model were based on available experimental data on Tpx, Trx, and TR enzymes (see Table S2 in Supplement1). The concentrations of the phenomenological enzymes (Pr, PSH, and Red) were determined as a 
result of the fitting of experimental data on the basal level of intracellular $\mathrm{H}_{2} \mathrm{O}_{2}$ concentration (Qutub and Popel, 2008). In the model we neglected the processes of $\mathrm{H}_{2} \mathrm{O}_{2}$ degradation through the oxidation of cellular proteins and the generation of free radicals by $\mathrm{H}_{2} \mathrm{O}_{2}$. As shown in (Adimora et al., 2010) the antioxidant enzyme cascade considered in the model plays a major role in maintaining of redox homeostasis and oxidative stress signalling in cells.

The model of the NRF2-dependent gene response to oxidative stress was based on the following experimental data. In the nucleus NRF2 binds with ARE promoter sites predominantly in a complex with small MAF protein initiating the transcription of NRF2dependent genes (Yamamoto et al., 2006). We assume that MAF is a nuclear protein which ensures accumulation of NRF2 in the nucleus ( $\mathrm{Li}$ et al., 2008) and the MAF homodimer acts as a repressor: its binding with ARE sites causes the repression of NRF2-dependent gene transcription (Yamamoto et al., 2006). In the calculation we ignored another repressor of ARE sites, BACH1 (Boutten, Goven, Artaud-Macari, Boczkowski, \& Bonay, 2011). In the model the complexes NRF2-MAF (activator) and MAF-MAF (repressor) control expression of genes encoding antioxidant enzymes. The processes of transcription and translation were modelled phenomenologically by Eq. (20) (Table S1 in Supplement I) describing Px enzyme induction. To obtain the kinetic parameters of the transcription complex formation we used in vitro data on binding of NRF2-MAF and MAF-MAF complexes with ARE sites (Yamamoto et al., 2006). In the model we took into consideration $10^{3}$ ARE sites under NRF2 control (Chorley et al., 2012) which all have approximately the same affinity to NRF2-MAF and MAF-MAF complexes. This assumption is in agreement with the fact that different nucleotide alterations in the ARE sequence do not change significantly its affinity to NRF2MAF and MAF-MAF complexes (Yamamoto et al., 2006). 


\section{Results}

3.1 Ovarian cancer cells show distinct growth rates that correlate with basal ROS

A growing body of evidence has suggested that the multitudes of mutations found in different cancerous cells not only cause irregularities and defects in normal cell cycle function, growth control and drug resistance, but also metabolic aberrations, oncogenically stimulated ROS stress and overall growth advantage (Benhar et al., 2001, Hlavatá et al., 2003). To examine the rates of cell proliferation, normal epithelial keratinocytes $(\mathrm{HaCaT})$ and a panel of ovarian cancer cell lines (OVCAR3, OVCAR4, PEO1, PEO4, PEO6 and SKOV3) were grown for 6 days. Cellular growth was monitored by counting the total viable cells daily. All the cell lines showed specific rates of proliferation. Differences were also noted for the three isogenic PEO cell lines (Fig 2a). Since the previous literature has shown endogenous ROS to induce proliferation in a variety of cell lines including ovarian (Ruiz-Ginés et al., 2000, Velarde et al., 2004, Hu et al., 2005, Paul et al. 2009), we next determined constitutive intracellular ROS levels in our cell line models by performing a general ROS assay (CELLROX ${ }^{\circledR}$, Life technologies). This was done in order to assess the correlation of ROS with growth rates. At 
different days of cell growth, $\mathrm{H}_{2} \mathrm{O}_{2}$ levels were also determined (AmplexRed ${ }^{\circledR}$ ) and quantified. We observed a consistent gradual build-up of intracellular $\mathrm{H}_{2} \mathrm{O}_{2}$ among all cell lines. The intracellular $\mathrm{H}_{2} \mathrm{O}_{2}$ production reached maxima by day 2 and remained stable thereafter with slight oscillatory fluctuation (Supplement II Fig. 1a). However, there were fundamental differences in the constitutive levels of both intracellular general ROS and $\mathrm{H}_{2} \mathrm{O}_{2}$ among the different cell lines. Higher levels of these were generally recorded with the cancerous cell lines relative to the normal $\mathrm{HaCaT}$ epidermal keratinocytes (Fig 2). Furthermore, there was a positive and statistically significant correlation between the intracellular total ROS and mean $\mathrm{H}_{2} \mathrm{O}_{2}$ levels $(\mathrm{r}=0.556, \mathrm{n}=35, \mathrm{p}=0.001)$. The correlation between total ROS and $\mathrm{H}_{2} \mathrm{O}_{2}$ persisted especially during the exponential phase of cellular expansion ( $\mathrm{r}=0.813, \mathrm{n}=35, \mathrm{p}<0.001$, (also see Supplement II Fig. $2 \mathrm{~b} \& \mathrm{c}$ ).

Mathematical fitting of the experimental growth data suggests a mixture of early exponential and late linear expansion pattern among the cell lines in general (Fig 2a). Linear regression of the cellular proliferation data, especially in the exponential phase (usually day 1-5), produced a mean growth rate constant $(\mu)$ range of $0.23-0.51$ among the cell lines studied (see methods). Table 2 lists the calculated growth rates from the proliferation assay, as well as ROS and $\mathrm{H}_{2} \mathrm{O}_{2}$ levels for all the cell lines studied. We found that while the mean growth rate constant for most of the cancer cells was greater than or equal to that of normal (HaCaT) cells (i.e. $>0.40$ ), lower $\mu$ values of 0.28 and 0.23 were recorded with the cancerous PEO4 and PEO6 respectively; 2-fold lower than that of their isogenic PEO1 cell line (matched by lower ROS values). Analysis of mean growth rates and accompanying ROS revealed that the production and maintenance (sequestration) of higher constitutive levels of intracellular ROS, in particular $\mathrm{H}_{2} \mathrm{O}_{2}$, in cancerous cell lines typically conferred higher and hierarchical growth advantage rates (Table 2 and Fig. 2a). Likewise hierarchical growth advantage rates that 
segregated in line with intracellular ROS and $\mathrm{H}_{2} \mathrm{O}_{2}$ levels were observed even among the isogenic cancer cell lines PEO1, PEO4 and PEO6 (Supplement II Fig. 2a \& b).

For the cancer cells, statistical analysis revealed a significant and positive correlation between $\mu$ and $\operatorname{ROS}(r=0.932, n=6, p=<0.05)$ and a positive but statistically not significant correlation with $\mathrm{H}_{2} \mathrm{O}_{2}(r=0.536, n=7, p=0.215$, Supplement II Fig. $2 b$ \& $c)$. The normally functioning $\mathrm{HaCaT}$ cells have a distinct profile, with growth rate in line with the majority of cancer cell lines but a reduced ROS level. This initial analysis of these elements of cellular behaviour revealed that cellular proliferation may control, or at least influence, stable and reo-adjustable dynamic ROS levels in a cell-dependent manner which may feed into pathways that in turn impact cellular physiology and growth.

3.2 Cells utilise basal ROS to control NRF2 subcellular compartmentalisation and association with KEAP1

ROS stress in cancer cells may exhibit an activated status of antioxidant response signalling as an adaptive mechanism to maintain sub lethal levels of ROS but still be sufficient to serve as signalling molecules. Consistent with this, previous studies have shown elevated levels of basal NRF2 and its substrates in tumours (Lister et al., 2011, Soini et al., 2001). The coupling of ROS with cellular proliferation that we found here is indicative of ROS being propagatable and transducible messenger molecules throughout the whole cell. This gives rise to variable levels of basal cellular redox in different cellular compartments and organelles that interconnect with the redox homeostatic regulatory network (Kietzmann, 2010). The NRF2- 
KEAP1 adaptive system is central to the maintenance of this redox balance and may be a critical determinant of sensing and coordinating the oxidative stress (ROS) response with cellular proliferation (Reddy et al., 2007). To explore this coordinating role, constitutive NRF2 and KEAP1 levels and NRF2 localisation in all cell lines were quantified. We first used known amounts of recombinant standard NRF2 and KEAP1 proteins to calibrate and generate reference standard curves for the absolute determination of the amount of both proteins in cells (Supplement II Fig. 3). Immunoblotting for endogenous proteins revealed that the cell lines contained highly detectable but dissimilar levels of both NRF2 and KEAP1 proteins (Fig. 3); cancer cells contained higher levels of total constitutive NRF2 and KEAP1 proteins than HaCaT cells. Among the cancer cell lines PEO1 exhibited highest levels of NRF2 while OVCAR4 showed the lowest. KEAP1 was highest in SKOV3 and lowest in OVCAR4. The stability of NRF2 is greatly influenced by the overall redox balance (Niture SK et al., 2013). We reasoned that the dissimilar levels of basal NRF2 and KEAP1 levels could be linked to the distinct intracellular ROS profiles determined earlier and as such could symbolise a consequence of basal ROS balance which in turn represents the metabolic and growth status of cells. We observed a statistically significantly correlation of ROS with KEAP1 levels $(r=0.794, n=7, p<0.05)$ and a correlation between the total intracellular ROS with constitutive total NRF2 ( $r=0.619, n=7, p=0.137$, Supplement II Fig. 4a) for our cell lines. Also the mean cellular $\mathrm{H}_{2} \mathrm{O}_{2}$ levels correlated significantly with both the constitutive total NRF2 $(r=0.893, n=7, p=0.007)$ and $\operatorname{KEAP}(r=0.857, n=7, p=0.014)$ proteins of the cells (Supplement II Fig. 4b). Interestingly the total constitutive NRF2 and KEAP1 levels in the cells correlated $(\mathrm{r}=0.692, \mathrm{n}=7, \mathrm{p}=0.085)$ albeit not statistically significant at two-tail but significant at one-tail test $(r=0.692, n=7, p<0.04$, Supplement II Fig. 4c). Moreover, the ratio of constitutive total KEAP1 to NRF2 is conserved across the cancer cell lines (1.5-4.6) in comparison with the substantially higher ratio for non-cancerous $\mathrm{HaCaT}$ epithelial 
keratinocyte (7.44, see Table 2). Thus the intracellular ROS levels among these cell lines appeared to not only correlate with and perhaps impact the earlier observed hierarchical growth rates but also modulate levels of total constitutive NRF2 and KEAP1 expression that in turn may maintain the observed growth advantage. Altogether, these results suggest that the growth rates of cells are linked with ROS including $\mathrm{H}_{2} \mathrm{O}_{2}$ generation and overall redox homeostasis, which serves to modulate basal NRF2 and KEAP1 levels and subcellular localisation of NRF2.

Previous reports have shown that within the nucleus NRF2 signals in pro-survival pathways (Niture et al., 2012a \& b, Ohta et al., 2003), triggers proliferation (Homma et al., 2009, Zhang et al., 2012) and is implicated in drug resistance (Wang et al., 2008). Similarly, knockdown of NRF2 has been reported to curb growth of tumour in vivo and in vitro (Manandhar et al., 2010, Singh et al., 2008). We next considered whether the high amount of ROS that we observed in cancer cells with enhanced growth rates could induce nuclear localisation of NRF2. This could then further feed into survival pathways ensuring a persistent growth advantage in cancer cells. Cellular fractionation followed by immunoblot analysis of NRF2 protein levels in our panel of ovarian cancer cell lines revealed a predominant nuclear localisation in PEO1 (80\% of total expressed), PEO4 (>75\%), PEO6 $(80 \%)$, and SKOV3 (80\%) ovarian cancer cell lines. In the non-cancerous HaCaT epidermal keratinocytes, NRF2 was mostly cytoplasmic in the basal state $(60 \%)$. Interestingly the OVCAR3 and OVCAR4 ovarian cancer cell lines were found to only contain $20-25 \%$ of total NRF2 in their nuclei while the remainder is cytoplasmic (Fig. 4a). The quality of cellular fractionation was determined by blotting for nuclear and cytoplasmic marker proteins (Supplement II Fig. 5a). Thus, the degree of nuclear retention of NRF2 and the overall ratio of nuclear to cytoplasmic distribution was similar in the three PEO cell lines and quite 
distinct from the OVCAR $3 \& 4$ and non cancerous HaCaT cell lines. In order to study the subcellular localisation of NRF2 at single cell level, we performed immunofluorescent labelling of NRF2 and confirmed the mostly nuclear localisation in PEO1, PEO4, PEO6 and SKOV-3 cells, in contrast to the predominantly cytoplasmic expression in OVCAR3, OVCAR4 and HaCaT cell lines (Fig. 4b). Association of NRF2 with KEAP1 was represented as merged images of immuno labelled NRF2 and actin staining followed by analysing their colocalisation (Fig. 4b, lower panels).

Based on these results we observe 3 major groups stratified on the basis of NRF2 localisation, ROS and growth rates: (1) HaCaT with average growth rate, lower ROS and mostly cytoplasmic NRF2; (2) SKOV3, PEO1, PE04 and PEO6 with average to high growth rate and average to high ROS and mostly showing nuclear localisation of NRF2; (3) OVCAR3 and OVCAR4 with average to high growth rate and average to high ROS and exhibiting low levels of nuclear NRF2. This grouping suggests differential cellular mechanism(s) for the use of the NRF2-KEAP1 status and compartmentalisation to control ROS redox balance in cells and to confer and regulate cellular proliferative capacity.

3.4 NRF2 localisation and stability are linked to ROS sequestration and maintenance potential

We next determined whether the observed variation in terms of proliferation and basal ROS with the accompanying adaption of distinct subcellular localisation pattern of NRF2 in different cell lines would result in differences in NRF2 protein stability. If indeed these 
factors influence NRF2 stability this would cause differences in the kinetics and half-life of NRF2 and could further confirm the link of NRF2-KEAP1 dynamics to the control of ROS homeostasis and cellular proliferative capacity. Thus the relationships between the basal NRF2 protein turnover (half-life), the basal ROS levels, the NRF2 localisation, and the proliferative capacity of the cells were assessed. First, the stability of NRF2 in exponentially growing cells following the inhibition of protein synthesis by cycloheximide chase assay was examined. Subsequent immunoblotting for NRF2 at different time points post cycloheximide treatment and the mathematical fitting of the experimental data by an exponential model of NRF2 degradation interestingly revealed differences in the stability and half-life of the protein among the cell lines examined (Fig. 5a \& 5b, for loading control see Supplement II Fig. 5b). Time-dependent degradation of NRF2 exhibited biphasic kinetics, requiring fitting experimental curves by two-exponential equations (see Methods) to characterise two distinct phases of degradation: 'fast' and 'slow'. The half-life parameters corresponding to fast and slow degradation, $\mathrm{T}_{\text {fast,NRF2 }}$ and $\mathrm{T}_{\text {slow,NRF2 }}$ respectively are given in Table 2 and the bestfitting curves are depicted in Figure 5b. The fastest degradation of NRF2 protein was recorded with the non-cancerous $\mathrm{HaCaT}$ keratinocyte with estimated $30 \mathrm{~s}$ of fast and 24 min of slow turnovers of NRF2 (Fig. 5a \& b, Table 2). The cancer cell lines have much more stable NRF2 levels and attenuated fast (25-75 fold slower) and slow (2-13 fold slower) degradation kinetics, as well as with much longer overall half-life (2-5 fold longer) when compared to HaCaT. Thus both inter and intra differences in the degradation kinetics of NRF2 among the HaCaT and various ovarian cancer cell lines appeared to support the earlier observed hierarchical segregation and clustering of the studied cells into 3 major groupings informed by key elements of cellular antioxidant pathway and growth behaviours. 
However, we could not find any relation between basal NRF2 or KEAP1 levels and degradation kinetics. Given the earlier significant correlation between $\mathrm{H}_{2} \mathrm{O}_{2}$ and both NRF2 and KEAP1, the influence of $\mathrm{H}_{2} \mathrm{O}_{2}$ levels on the degradation kinetics of NRF2 was examined. The mean $\mathrm{H}_{2} \mathrm{O}_{2}$ levels were found to positively and significantly correlate with the fast degradation kinetics $(r=0.679, n=7, p=0.047)$ and half-life $(r=0.703, n=7, p=0.039)$ of NRF2 albeit at one-tailed level, but not with the model generated slow degradation kinetics $(\mathrm{r}=0.643, \mathrm{n}=7, \mathrm{p}=0.06$, see Supplement II Fig. $6 \mathrm{a} \& \mathrm{~b})$. This correlation suggested that cells carrying higher basal $\mathrm{H}_{2} \mathrm{O}_{2}$ levels have greater NRF2 stability, which is consistent with the classical model of NRF2 regulation. While basal NRF2, KEAP1 and ROS levels together with growth rate $(\mu)$ did not correlate with the half-life of NRF2, KEAP:NRF2 ratio did however exhibit inverse correlation ( $\mathrm{r}=-0.879, \mathrm{n}=7, \mathrm{p}<0.05$, see Supplement II Fig. 6c). These findings suggest that general cellular ROS levels, in particular $\mathrm{H}_{2} \mathrm{O}_{2}$, have direct effect on basal NRF2 and KEAP1 protein levels, which in return control and maintain redox balance. Cell specific alterations of these factors seem to influence the basal protein stability of NRF2 and may determine overall redox potential in a tissue specific manner.

3.5 Distinct cellular response of cancer cells to redox perturbation is explained by dynamics of NRF2 nucleocytoplasmic shuttling and compartmentalisation

It is conceivable that ROS (including $\mathrm{H}_{2} \mathrm{O}_{2}$ ), redox balance in cells and the NRF2-KEAP1 dynamics are intricately linked and influenced by cellular ROS production and sequestration potentials. We hypothesised that the distinctive constitutive ROS maintained by cells might be as a result of their varying proliferative and metabolomic profiles, which would subsequently affect nuclear localisation and retention of NRF2. Once in the nucleus, NRF2 
would be more stable, and this stability would ultimately influence its half-life to inform its antioxidant function as well as signal back into proliferative pathways. Our hypothesis was that based on basal redox profile, different cells may react with different kinetics to the same level of exogenous sources of pro- and antioxidants. Specifically, cells with higher ROS or pre-existing nuclear NRF2 might represent a readily active antioxidant system and may robustly remove exogenous oxidative radicals with faster kinetics. To test this, we exogenously added $5 \mu \mathrm{M} \mathrm{H}_{2} \mathrm{O}_{2}$ to the cells followed by assaying for $\mathrm{H}_{2} \mathrm{O}_{2}$ levels in the media over time. This allowed us to assay for cellular antioxidant potential based on kinetics of $\mathrm{H}_{2} \mathrm{O}_{2}$ removal.

First of all, we found that the antioxidant pathway is rapidly activated following oxidative challenge in all our cell lines as robust scavenging and fast $\mathrm{H}_{2} \mathrm{O}_{2}$ reduction kinetics was observed (Fig. 6). Secondly, the reduction of $\mathrm{H}_{2} \mathrm{O}_{2}$ followed an damping oscillatory pattern which could be indicative of engagement of feedback loops. Thirdly, we found distinct differences in the kinetics of reduction of $\mathrm{H}_{2} \mathrm{O}_{2}$ signal overtime. PE04 demonstrated most efficient reduction and sequestration capacity with only $10 \% \mathrm{H}_{2} \mathrm{O}_{2}$ relative to time 0 remaining after 10 min. PE04 and PE06 had similar levels of $\mathrm{H}_{2} \mathrm{O}_{2}$ after 20 minutes; OVCAR3 showed a similar profile. SKOV3 cell line, which was found to have the highest basal ROS neutralised exogenous $\mathrm{H}_{2} \mathrm{O}_{2}$ only minimally to restore its higher basal levels. Interestingly, although $\mathrm{HaCaT}$ cell line had the lowest basal ROS, it still failed to neutralise external $\mathrm{H}_{2} \mathrm{O}_{2}$ as efficiently and fast as its PEO or OVCAR counterparts. Thus all cells treated with $5 \mu \mathrm{M} \mathrm{H}_{2} \mathrm{O}_{2}$ revealed a robust but cell specific time-dependent $\mathrm{H}_{2} \mathrm{O}_{2}$ scavenging abilities and reducing kinetics of cells, which is likely informed by the cellular dynamics of the NRF2 antioxidant signalling response. Altogether, this further strengthened the assumption that cells with different growth rates, basal ROS and NRF2 stability have different efficiencies of their 
antioxidant system. Moreover, the fact that addition of external ROS in cancer cells was quickly neutralised to the level of their corresponding basal ROS (but not in normal cell line) demonstrated cancer cell's addiction to a specific higher level of basal ROS.

Sub-cellular protein trafficking and localisational control of NRF2 is a key element in the regulation of NRF2 mediated antioxidant response (Jain AK et al., 2005, Theodore M et al., 2008). The localisational control and compartmentalisation of NRF2 has also been linked to its protein stability (Itoh K et al., 2003, Niture SK et al., 2011), a key element that we found to be different in our cell line models. Hence, to extend our line of investigation, we next perturbed the redox balance within the cells and in parallel, studied its effects on NRF2 localisation in cell dependent manner. This was also done to identify whether the differential kinetics of $\mathrm{H}_{2} \mathrm{O}_{2}$ scavenging assay could be related with NRF2 trafficking and localisation dynamic following pro-oxidant challenge. Using HaCaT, PEO1 and OVCAR3 cell lines to represent and exemplify the 3 clustered groups, perturbation of basal cellular redox homeostasis was done by exogenous oxidation or reduction of the cellular environment with $100 \mu \mathrm{M} \mathrm{H}_{2} \mathrm{O}_{2}$ a pro oxidant or $10 \mathrm{mM} \mathrm{N}$-Acetyl Cysteine (NAC), a well-known ROS scavenger, respectively for different time points as indicated.

To demonstrate that our treatment regimes chosen indeed altered cellular ROS, cells were subjected to time course treatments of the above pro and antioxidants and assayed for cellular ROS content (Supplement II Fig. 7). Immunofluorescent labelling of NRF2 was carried out in the three cell lines using the NRF2 primary antibody (Santacruz, UK) and an Alexa fluor 488 conjugated anti rabbit secondary antibody (Invitrogen, UK) to label endogenous NRF2 (Green fluorescence). DAPI staining (Vectasheild labs) was performed on the same cells to 
stain nuclear DNA and provide for nuclear reference (Blue fluorescence). As previous studies have reported that the cytoplasmic KEAP1 is localised at the Actin filaments (Kang et al., 2004), we also performed actin staining (red fluorescence) to indicate cytoplasmic localisation of NRF2 in KEAP1 bound state (Red fluorescence). Merging was performed between the images captured in different channels to indicate and differentiate nuclear NRF2 and extra nuclear cytoplasmic NRF2. Whole cell, nuclear and cytoplasmic fluorescent intensities were individually measured and quantified with the intensity of untreated cells (UT) set as 100\% (Fig. 7).

We found that generally there was gradual reduction or increase in total NRF2 levels in the cells following treatment with $\mathrm{NAC}$ or $\mathrm{H}_{2} \mathrm{O}_{2}$ respectively (Fig. $7 \mathrm{~b}$, e \& h). NAC treatment caused reduction in nuclear fluorescence of NRF2 with a corresponding transient accumulation in cytoplasm. However, extension of the treatment time reduced the cytoplasmic fluorescence of NRF2 with an overall decrease in total fluorescence indicating degradation in the cytoplasm (Fig. $7 \mathrm{c}, \mathrm{f} \& \mathrm{~g}$ ). In contrast, $\mathrm{H}_{2} \mathrm{O}_{2}$ treatment caused nuclear accumulation of NRF2 with a corresponding reduction in cytoplasmic fluorescence indicating nuclear trafficking and increased total intensity exhibiting an overall increase in protein levels. We found that the dynamics of such nuclear-cytoplasmic shuttling as well as overall total changes in NRF2 expression following treatments were different among the cell lines examined. It is interesting to note that while the overall kinetics of NRF2 induction following $\mathrm{H}_{2} \mathrm{O}_{2}$ was similar, there was a faster nuclear accumulation of NRF2 in PEO1 and OVCAR3 as compared to $\mathrm{HaCaT}$ (compare Fig. $7 \mathrm{c}$ and $\mathrm{i}$ with $\mathrm{f}$ ). This is consistent with our $\mathrm{H}_{2} \mathrm{O}_{2}$ reduction assay where faster removal of $\mathrm{H}_{2} \mathrm{O}_{2}$ was noted for these cell lines as compared to HaCaT. Furthermore, this study also supported our earlier assumption that higher nuclear NRF2 in cancer cell lines e.g. PEO1 (Fig. 3) might be maintained because of high 
constitutive ROS (Fig. 2) as neutralisation of the basal ROS reduced nuclear NRF2 in all cell lines examined (Fig. 7a, d \& g). Thus, it is suggested that while cell specific proliferation rates maintain a basal level of ROS, this redox status in turn influences the constitutive and induced NRF2 activity. All these elements of growth and signalling converge together to inform the redox potential of a cell and determine overall antioxidant efficiency and capacity (Fig. 6). The quantitative immunofluorescence data generated in these experiments was used to further parameterise our NRF2 dependent in silico model of antioxidant pathway and we report on model findings below.

\subsection{Cancer cells are addicted to elevated levels of basal ROS}

One of the assumptions made in our study is that the different levels of basal ROS established across cell lines is due to their distinct growth rates and that cancer cells might be addicted to such elevated ROS (see earlier correlation of ROS and growth rate for cancer cells). The role of physiological ROS as a signalling molecule in key signalling pathways (D'Autréaux B et al., 2007) including proliferation (Ruiz-Ginés et al., 2000, Valarde et al., 2004, Lister et al., 2011, Wang et al., 2013) has been shown in a number of studies. In order to illustrate that physiological ROS might be involved in maintaining high growth rates, a cellular proliferation assay was performed in the presence of $10 \mathrm{mM}$ NAC. Moreover, to study the degree of resistance of cells to exogenous ROS, proliferation was also performed in the presence of $20 \mu \mathrm{M} \mathrm{H}_{2} \mathrm{O}_{2}$. Again, the HaCaT, PEO1 and OVCAR3 cell lines were used to represent the 3 different clusters of cellular behaviours identified earlier. 
As expected, we found different sensitivities of the three cell lines to the treatments. Treatment of the cells with $\mathrm{H}_{2} \mathrm{O}_{2}$ was most inhibitory to cell growth in the $\mathrm{HaCaT}$ cell line followed by OVCAR3 cells (Fig. 8). PEO1 cell line was found to be minimally inhibited by $\mathrm{H}_{2} \mathrm{O}_{2}$ treatment. Interestingly, neutralisation of basal ROS through NAC treatment substantially inhibited the proliferation of the two cancer cell lines and overall slowed the growth rates. This validates our earlier assumption that cancer cells might be addicted to elevated levels of ROS that may feed into proliferative pathways and maintain a high growth rate, e.g. OVCAR3 with a higher basal ROS was more sensitive to NAC than PEO1 with slightly lower basal ROS (compare Fig. 2 \& 8). However, in HaCaT cells, NAC paradoxically increased the proliferation rate indicating that this addiction to ROS might specifically be an ovarian cancer cell phenomenon. Overall, the two ovarian cancer cell lines were more resistant to redox perturbation. Linear regression of the proliferation data and following these treatments produced similar results (Supplement II Fig. 8). Interestingly the inhibitory effect of NAC on the growth of the cancer cell lines was greatest with OVCAR3 and OVCAR4 and moderate with SKOV3 and PEO6 (data not shown). Thus ROS scavenging with the antioxidant NAC slows down the proliferation of ovarian cancer cells hierarchically, but not in normal epithelial keratinocytes. These experiments revealed that the proliferation

of these cells was dependent on basal constitutive ROS levels. Furthermore, enhanced hierarchical pro-oxidant scavenging or sequestration capacity was observed among the cancer cell lines and appeared to be compromised or attenuated in normal HaCaT keratinocytes.

\subsection{Modelling NRF2-KEAP1 dependent redox regulation}


We used the kinetic model of NRF2 signalling to investigate the mechanism of NRF2-KEAP1 dependent redox regulation in different cells in a resting condition and in response to oxidative stress. First we modelled a basal level of $\mathrm{H}_{2} \mathrm{O}_{2}$ corresponding to redox homeostasis in proliferating cells. The model reproduces the experimental steady state concentration of $\mathrm{H}_{2} \mathrm{O}_{2}(0.5 \mu \mathrm{M})$, which was observed to be in the range of $0.5 \mu \mathrm{M}$ to $1 \mu \mathrm{M}$ for the different cells under investigation (Table 2).

Modelling of the regulation of redox homeostasis in the cells under oxidative stress was carried out on the basis of the experimental data of degradation kinetics for extracellular $\mathrm{H}_{2} \mathrm{O}_{2}$ measured in the different cells (Fig. 6). The results of the modelling of degradation kinetics following external $5 \mu \mathrm{M} \mathrm{H}_{2} \mathrm{O}_{2}$ are shown in Figure 9. The model reproduced the nonexponential degradation kinetics of $\mathrm{H}_{2} \mathrm{O}_{2}$, characterized by fast decay of $\mathrm{H}_{2} \mathrm{O}_{2}$ with half-life $T_{\text {fast }, \mathrm{H}_{2} \mathrm{O} 2}=5 \mathrm{~min}$, followed by slow degradation to the basal level of $\mathrm{H}_{2} \mathrm{O}_{2}$. The modelling showed that external $5 \mu \mathrm{M} \mathrm{H}_{2} \mathrm{O}_{2}$ induces an increase in the intracellular level of $\mathrm{H}_{2} \mathrm{O}_{2}$ during $T_{\text {fas }, \mathrm{H} 2 \mathrm{O} 2}$ followed by its fast recovery to the basal $\mathrm{H}_{2} \mathrm{O}_{2}$ concentration due to antioxidant cellular systems. Extra intracellular $\mathrm{H}_{2} \mathrm{O}_{2}$ degrades through the cascade of oxidation/reduction reactions of the enzymes involving in ROS cellular scavenging systems (module 9, Fig. 1). The model reproduced the typical kinetics of peroxidase oxidised during treatment cells by $\mathrm{H}_{2} \mathrm{O}_{2}$ (Adimora et al., 2010) (blue line, Fig. 9). The total concentration of peroxidase (Px) in the model increased, and this indicates a NRF2-KEAP1-dependent expression of peroxidase in response to redox perturbation (red line, Fig. 9). The switching on of the Nrf2-KEAP1 dependent genetic regulation causes maximum production of peroxidase enzymes at 1 hour after $\mathrm{H}_{2} \mathrm{O}_{2}$ treatment and the subsequent slow switching off of the genetic regulation occurs following attainment of a basal level of $\mathrm{H}_{2} \mathrm{O}_{2}$. 
To analyse the NRF2-KEAP1-dependent mechanism of genetic regulation of the antioxidant enzymes we first described the steady state of NRF2, determined by a KEAP1dependent mechanism of NRF2 degradation in the cytoplasm (module 1, Fig. 1). The kinetic characteristics of this mechanism were obtained from our NRF2 degradation experiments following CHX treatment: CHX action was modelled by setting a zero value for the reaction rate of NRF2 expression. Fig. 10 shows the model reproduced the experimental data for Nrf2 degradation (black lines and points respectively in Figs.10a and 10b). The modelled half-life for fast degradation $T_{\text {fast }, N r f 2}=30 \mathrm{~s}$ for HaCaT and $T_{\text {fast }, N r f 2}=10$ min for PE01 cells was in accordance with our experimental data (Table 2). We then calculated separately the degradation kinetics of NRF2 in the cytoplasm and the nucleus (Figs. 10a and 10b, red and blue lines respectively). The fast kinetics of NRF2 degradation is due to NRF2 degradation in the cytoplasm through a KEAP1-dependent mechanism. According to the model, the slow kinetics of NRF2 degradation is defined by the slow release of NRF2 from the nucleus (module 3, Fig. 1) followed by its degradation in the cytoplasm through a KEAP1-dependent mechanism. The contribution of these fast and slow processes to the total degradation kinetics depends on the fraction of cytoplasmic and nuclear NRF2 in the cells: a prevalence of slow kinetics is attributed to cells with a high fraction of the basal nuclear NRF2 level. In the calculation, the ratio of the steady state concentrations of cytoplasmic to nuclear NRF2 was 50:50 and 20:80 for $\mathrm{HaCaT}$ and PEO1cells respectively (see initial point at $\mathrm{t}=0$ in Figs. 10a and 10b) which correspond to our experimental data (Table 2). The different distribution of NRF2 between cytoplasm and nucleus in the model for HaCaT and PEO1 cells is defined by different $\mathrm{H}_{2} \mathrm{O}_{2}$ levels in these cells: $490 \mathrm{nM}$ and $630 \mathrm{nM}$ respectively (Table 2). A higher level of $\mathrm{H}_{2} \mathrm{O}_{2}$ in PEO1cells defines a higher nuclear concentration of NRF2 in PEO1cells in comparison with HaCaT cells. 
To analyse the kinetics of the NRF2 redistribution between the cytoplasmic and nuclear compartments in response to redox perturbation we modelled NRF2 kinetics during oxidation and reduction in the intracellular environment by cell treatment with $100 \mu \mathrm{M} \mathrm{H}_{2} \mathrm{O}_{2}$ and $10 \mathrm{mM}$ NAC, respectively (see Fig. 7). In line with experimental data, modelling showed that extra $\mathrm{H}_{2} \mathrm{O}_{2}$ causes an increase in total NRF2 (black points and lines in Fig. 11a) that occurs due to the suppression of KEAP1-dependent degradation of NRF2 as a result of KEAP1 oxidation. Increasing total NRF2 increases passive transport of NRF2 to the nucleus and its subsequent accumulation due to binding with nuclear protein MAF (blue lines and points in Fig. 11a). In the model the cytoplasmic concentration of NRF2 changed slightly; in experimental data a slight decrease is shown (red lines and points respectively in Fig. 11a). We suggest that this faster trafficking of NRF2 from cytoplasm to nucleus may result from active transport of NRF2 through the nuclear membrane in additional to the passive diffusion in the model (Boutten et al., 2011).

In silico modelling of the reduction in the intracellular environment by NAC showed opposing NRF2 kinetics to those observed in the cell oxidation experiment (Fig. 4). The model describes satisfactorily decreases in total, nuclear and cytoplasmic NRF2 concentrations as a result of the reduction in the intracellular environment (black, blue and red lines and experimental points respectively in Fig. 11b). The decrease in total NRF2 is due to a reduction in KEAP1 by thioredoxin and the formation of KEAP1-NRF2 complexes in the cytoplasm followed by the degradation of NRF2 in the cytoplasm. A decrease in cytoplasmic NRF2 leads to a diffusion of NRF2 from nucleus effected by a decreasing nuclear concentration of NRF2 and a switching off of expression of NRF2-dependent genes. 
The KEAP1-NRF2-dependent regulation mechanism in the model reflects different perturbations to redox homeostasis and includes the following interconnected processes: KEAP1 oxidation/reduction; KEAP1-dependent mechanism of NRF2 degradation; nuclear to cytoplasmic shuttling of NRF2; and NRF2 induced formation of a transcription factor leading to transcription of genes encoding antioxidative enzymes. The gene regulation by nuclear NRF2 forms a negative feedback: an increase of nuclear NRF2 causes expression of antioxidative enzymes that in turn cause a decrease in total and nuclear NRF2 concentrations due to reduction of an oxidized form of KEAP1 (module 8, Fig. 1). To analyse the role of this negative feedback in the whole regulatory mechanism we calculated the regulation curve of this system, i.e. the dependence of the control parameter, NRF2 level, on the controlled parameter, steady state concentration of $\mathrm{H}_{2} \mathrm{O}_{2}$ (Fig. 12). This $\mathrm{NRF} 2-\mathrm{H}_{2} \mathrm{O}_{2}$ regulation curve shows an S-type characteristic and defines the mutual dependence between NRF2 and $\mathrm{H}_{2} \mathrm{O}_{2}$ concentrations in cells: $\mathrm{H}_{2} \mathrm{O}_{2}$ level defines NRF2 concentration in the nucleus; in turn NRF2 controls $\mathrm{H}_{2} \mathrm{O}_{2}$ in cells.

Analysis of this control loop based on the NRF2- $\mathrm{H}_{2} \mathrm{O}_{2}$ regulation curve allows tracking of the dynamics when moving from low to high endogenous concentrations of $\mathrm{H}_{2} \mathrm{O}_{2}$. An increasing level of endogenous $\mathrm{H}_{2} \mathrm{O}_{2}$ in the model was obtained by increasing the rate of $\mathrm{H}_{2} \mathrm{O}_{2}$ synthesis $\left(V_{H 2 O 2 p r o d}\right)$ in cells. An increase in $\mathrm{H}_{2} \mathrm{O}_{2}$ in the range of $100 \mathrm{nM}-700 \mathrm{nM}$ causes a gradual growth of NRF2 concentration due to a slowing down of KEAP1-dependent degradation of NRF2 as a result of KEAP1 oxidation. In this region of $\mathrm{H}_{2} \mathrm{O}_{2}$ concentration, a basal level of antioxidative enzymes in the cells is enough to maintain a steady state of $\mathrm{H}_{2} \mathrm{O}_{2}$ in the range up to $700 \mathrm{nM}$, shown in Fig. 12 on the forward branch of the curve from the 
origin up to the sharp change in direction. A further increase in the rate of $\mathrm{H}_{2} \mathrm{O}_{2}$ synthesis causes fast growth of both total and nuclear NRF2 concentrations that induces the NRF2dependent genetic response of the cells to high level of $\mathrm{H}_{2} \mathrm{O}_{2}$ : an increasing level of transcription factor NRF2 in the nucleus causes expression of antioxidative enzyme peroxidase (Px) in the model (module 6, Fig. 1). In turn, an increasing level of Px leads to a decreasing $\mathrm{H}_{2} \mathrm{O}_{2}$ concentration that corresponds to the reverse branch on the S-type regulation curve in Fig. 12. Note the reverse branch of the S-type regulation curve is stable: cells can have NRF2 and $\mathrm{H}_{2} \mathrm{O}_{2}$ concentrations situated on this branch. There is an inverse dependence between the controlling parameter, NRF2 level, and controlled parameter, level of $\mathrm{H}_{2} \mathrm{O}_{2}$, on this reverse branch of the NRF2- $\mathrm{H}_{2} \mathrm{O}_{2}$ regulation curve opposed to a direct dependence on the forward branch. At a still higher rate of $\mathrm{H}_{2} \mathrm{O}_{2}$ synthesis a saturated level of total and nuclear NRF2 $(80 \%)$ is attained at which the expression of NRF2-dependent genes proceeds at a maximum rate. The saturated level of NRF2 is defined as a mainly nuclear concentration of MAF and cytoplasm/nucleus equilibrium of free NRF2. The characteristic of the $\mathrm{NRF} 2-\mathrm{H}_{2} \mathrm{O}_{2}$ regulation curve at higher rates of $\mathrm{H}_{2} \mathrm{O}_{2}$ synthesis alters significantly: the reverse branch changes to a saturated branch. On this saturated branch, the further increase of $V_{\text {H2O2prod }}$ leads to an increase of a steady state concentration of $\mathrm{H}_{2} \mathrm{O}_{2}$ which is maintained by the maximum expression rate of antioxidant enzymes. On this saturated branch a regulatory role of NRF2 is in maintaining the maximum expression rate of antioxidant enzymes to support high level of steady state concentration of $\mathrm{H}_{2} \mathrm{O}_{2}$.

To validate this model behaviour we compared the NRF2- $\mathrm{H}_{2} \mathrm{O}_{2}$ regulation curve with the measurements of total and nuclear NRF2 levels and endogenous $\mathrm{H}_{2} \mathrm{O}_{2}$ concentration obtained in our experiments for the seven cell lines (see points, Fig. 12 taken from Table 2). The theoretical regulation curve qualitatively describes a complex NRF2- $\mathrm{H}_{2} \mathrm{O}_{2}$ relationship in 
the different cells. NRF2 and $\mathrm{H}_{2} \mathrm{O}_{2}$ concentrations in HaCaT and OVCAR4 cells are located in the vicinity of the forward branch of the regulation curve where there is a direct dependence of total and nuclear NRF2 concentration on $\mathrm{H}_{2} \mathrm{O}_{2}$ concentration. NRF2 and $\mathrm{H}_{2} \mathrm{O}_{2}$ concentrations in PEO4 cells, having lower $\mathrm{H}_{2} \mathrm{O}_{2}$ and higher NRF2 levels than OVCAR4 cells, lie near the reverse branch of the regulation curve where NRF2 regulation leads to an inverse dependence between NRF2 and $\mathrm{H}_{2} \mathrm{O}_{2}$ concentrations. NRF2 and $\mathrm{H}_{2} \mathrm{O}_{2}$ concentrations for PE04, PE01, OVCAR3, and SKOV3 cells lie in the range of the saturated branch of the regulation curve where maximum total and nuclear concentration of NRF2 do not change when $\mathrm{H}_{2} \mathrm{O}_{2}$ level increases. Although PE01 total and nuclear NRF2 concentrations lie much higher than those defined by the saturated branch we assume that PE01 cells relate to the saturated branch of the regulation curve because of maximum fraction of nuclear NRF2 $(83 \%)$ in this cell line. This deviation may be due to the fact that the $\mathrm{NRF} 2-\mathrm{H}_{2} \mathrm{O}_{2}$ regulation curve was calculated for "a reference cell" with parameters being independent of the features of different cell lines (see Supplement I).

\section{Discussion}

ROS generation is an inevitable outcome of cellular metabolism in all mammalian cells. ROS have been implicated in numerous normal and disease cellular processes including proliferation, differentiation (Choe et al., 2012; Ho et al., 2013) cell death (Gao et al., 2013, ageing and carcinogenesis (Diehn et al., 2009; Hempel et al., 2009; Liu et al., 2012; Okoh et al., 2013). The apparent paradox between the positive role of ROS as a cellular signalling molecules and its negative role as a cellular intoxicant appears to be highly dependent on the production, management and resolution of its intracellular concentration. Answering key questions including how mammalian cells precisely coordinate, handle and manage ROS levels to inform and execute particular processes will shed light on this paradox. While ROS 
and antioxidant enzyme defenses have been studied in many tumours (Chaiswing et al., 2011; Laurent et al., 2005), the role of these important molecular species in ovarian cancer has not been examined in detail. Here, we used experimentally derived quantitative data to define several key components that control the redox characteristics of ovarian cancer cells and determine the role of oxidative stress on the addiction of ovarian cancer cells to ROS, which might confer and maintain cellular proliferation advantage.

We first determined proliferation characteristics of normal epithelial keratinocytes (HaCaT) and a panel of ovarian (OVCAR3, OVCAR4, PEO1, PEO4, PEO6 and SKOV3) cancer cell lines under basal redox homeostasis and evaluated the dynamics of ROS production and sequestration capacity. It appeared that $\mathrm{H}_{2} \mathrm{O}_{2}$ controls or at least impacts on stable and steady dynamic levels of ROS in a cell-dependent manner to inform cellular proliferation. We found a positive correlation between cellular total ROS, $\mathrm{H}_{2} \mathrm{O}_{2}$ and growth rate. Cell proliferation could be altered by perturbing the basal redox homeostasis using exogenous $\mathrm{H}_{2} \mathrm{O}_{2}$ and the antioxidant NAC. It is evident that the production and maintenance of higher constitutive levels of intracellular $\mathrm{H}_{2} \mathrm{O}_{2}$ in ovarian cancer cell lines conferred higher and hierarchical growth advantage rate, even among isogenic cancer cell lines (PEO1, PEO4 and PEO6). This is consistent with the literature regarding other cells and cancer types (Ngô et al., 2009; Chaiswing et al., 2011), although the manner by which this potential is achieved varies widely.

Next, we sought to identify a general net integrative switchable and adjustable sensing, filtering, transducer and effector system that may reasonably connect intracellular ROS, in particular $\mathrm{H}_{2} \mathrm{O}_{2}$, with proliferation in ovarian cancer cells. We hypothesised that the NRF2- 
centred system is a key redox interconnectivity node and interface between ROS, cytoprotection and the regulation of proliferation in ovarian cancer cells. Accordingly we quantified and evaluated the levels of both NRF2 and KEAP1 in these cell lines, as well as the stability and localisation of NRF2. Interestingly, the observed hierarchical growth advantage rates among these cell lines appeared to be informed by not only the intracellular ROS levels but also by the total constitutive NRF2 and KEAP1 status. Our findings suggest that general cellular ROS levels, in particular $\mathrm{H}_{2} \mathrm{O}_{2}$, modulate basal cellular NRF2 and KEAP1 protein levels.

We observed differences among the different cells in the sub-cellular localisation of NRF2 and considered whether the observed variation in terms of proliferation, basal ROS, altered NRF2 protein levels and/or its nuclear localisation also results in enhanced NRF2 protein stability. Any increased NRF2 stability would cause differences in the kinetics and half-life of NRF2 and could further support the links among NRF2-KEAP1 dynamics, control of ROS homeostasis and proliferative capacity. Modelling and analysis of NRF2 degradation revealed differences in the stability and half-life of the protein among the cell lines. These differences suggest there are different cellular mechanism(s) governing NRF2-KEAP1 dynamics, status and compartmentalisation to control the ROS redox balance in cells. Mathematical fitting and modelling of NRF2 degradation data showed the time-dependent degradation of NRF2 to be biphasic, consisting of fast and slow degradation stages. The fastest degradation was recorded in HaCaT cells: estimated fast (30 s) and slow (24 min) turnovers of NRF2 with an overall half-life of approximately $5 \mathrm{~min}$. In contrast, NRF2 is much more stable in cancer cell lines: the fast and slow phases were 25-75 fold and 2-13 fold slower than for HaCaT and the NRF2 half-life was 2-5 fold longer. The fast degradation kinetic is explained by the classical and predominant cytoplasmic NRF-KEAP1-CUL3-dependent degradation mechanism (Baird et 
al., 2013; McMahon et al., 2004). The slow degradation kinetic may represent the GSK- $\beta$ and the $\beta$ TRCP dependent mechanism of NRF2 destruction (Chowdhry et al 2013) or the KPNA6-KEAP1-dependent nuclear shuttling and export of NRF2 for presentation to CUL3 and subsequent degradation in the cytoplasm (Sun et al., 2011). It is also conceivable that the slow degradation kinetic is explained by a yet to be determined mechanism of NRF2 degradation in the nucleus as is the case with other transcription factors or nuclear localised proteins (Cohen et al 2013; Song et al., 2011).

To confirm that the variation in nuclear localisation among different cell lines is caused by basal levels of ROS being maintained to support proliferation in cancer cells, cells were treated with either $\mathrm{N}$-Acetyl cysteine or $\mathrm{H}_{2} \mathrm{O}_{2}$ to perturb the basal redox homeostasis. While $\mathrm{N}$-Acetyl cysteine caused cytoplasmic sequestration of NRF2 with a concomitant decrease in its nuclear accumulation, $\mathrm{H}_{2} \mathrm{O}_{2}$ showed a contrary effect. All cells when treated with $\mathrm{H}_{2} \mathrm{O}_{2}$ showed a robust but differential antioxidant signalling response as they scavenge and sequester $\mathrm{H}_{2} \mathrm{O}_{2}$ in a time dependent manner. The cells also showed remarkable differences in the kinetics of signal reduction that in most cases correlated well with the half-life of NRF2 and NRF2:KEAP1 ratio. Overall the dynamics of the nuclear-cytoplasmic shuttling as well as overall total changes in NRF2 expression following the treatments were different among the cell lines examined. Interestingly, neutralisation of basal ROS through NAC treatment substantially inhibited the proliferation of cancer cell lines by reducing growth rates. On the contrary, NAC increased the proliferation rate of HaCaT cells. However, cancer cells appeared to resist the growth inhibitory effect of $\mathrm{H}_{2} \mathrm{O}_{2}$ better than normal cell line. This validates our earlier assumption that cancer cells might be addicted to elevated levels of ROS that may feed into proliferative pathways to maintain a high growth rate. This addiction is then in addition to the implicated role of ROS in promoting the acquisition of stemness and 
metastatic phenotypes in cancers (Alexis, et al.; Shimojo etal., 2013; Raha et al., 2014). However, it is pertinent to mention that NAC has been shown to promote the proliferation of prostate cancer cells (Erin et al., 2012)

To more fully understand cellular responses to these different experimental perturbations to redox homeostasis we constructed a model of intracellular signalling that represents key response mechanisms to oxidative stress. We profiled the degradation kinetics of intracellular $\mathrm{H}_{2} \mathrm{O}_{2}$ following the addition of external $5 \mu \mathrm{M} \mathrm{H}_{2} \mathrm{O}_{2}$ and determined that cellular response was governed by a NRF2-KEAP1 dependent mechanism. This mechanism depended on the dynamic allocation of NRF2 between the cytoplasm and the nucleus and we obtained good agreement between the model and experimental data following oxidant and antioxidant perturbations (Fig. 11). We then proposed that the dynamics of $\mathrm{NRF} 2-\mathrm{H}_{2} \mathrm{O}_{2}$ regulation defines a relationship between total and nuclear NRF2 level and endogenous $\mathrm{H}_{2} \mathrm{O}_{2}$ in various cell lines.

The model predicted different redox states of cells, characterized by the controlling parameters, NRF2 concentration, and the controlled parameters, a steady state of $\mathrm{H}_{2} \mathrm{O}_{2}$. At a low rate of $\mathrm{H}_{2} \mathrm{O}_{2}$ synthesis in the cells, the basal concentrations of $\mathrm{H}_{2} \mathrm{O}_{2}$ and NRF2 lie on the forward branch of the NRF2- $\mathrm{H}_{2} \mathrm{O}_{2}$ regulation curve in Figure 12. When the rate of $\mathrm{H}_{2} \mathrm{O}_{2}$ synthesis is increased, the basal concentrations of $\mathrm{H}_{2} \mathrm{O}_{2}$ and NRF2 can lie on forward, reverse or saturated branches of the regulation curve. In this region of the $\mathrm{H}_{2} \mathrm{O}_{2}$ synthesis rate there is a steep inverse dependence between NRF2 and $\mathrm{H}_{2} \mathrm{O}_{2}$ levels, and concentration of $\mathrm{H}_{2} \mathrm{O}_{2}$ is in a narrow range of $500 \mathrm{nM}-700 \mathrm{nM}$ while NRF2 concentration can vary significantly. If the rate of $\mathrm{H}_{2} \mathrm{O}_{2}$ synthesis increases further in the cells, the steady state of $\mathrm{H}_{2} \mathrm{O}_{2}$ and NRF2 can 
lie only on the saturated branch of the regulation curve with various concentrations of $\mathrm{H}_{2} \mathrm{O}_{2}$ and a constant maximum nuclear NRF2 level. It is likely that the individual $\mathrm{NRF} 2-\mathrm{H}_{2} \mathrm{O}_{2}$ regulation curve of each cell line or a specific group of cell lines differs. As our analysis showed, the regulation curve particularly depends on the KEAP1 and MAF concentrations, and these vary in different cell lines (e.g. see KEAP variation in Table 2). Nevertheless the present calculation of the reference NRF2- $\mathrm{H}_{2} \mathrm{O}_{2}$ regulation curve shows a complex behaviour with direct and inverse dependencies between NRF2 and $\mathrm{H}_{2} \mathrm{O}_{2}$ levels in cells that in turn define a complex relationship between endogenous NRF2 and $\mathrm{H}_{2} \mathrm{O}_{2}$ concentrations in cells. Note the regulation curve has the S-type feature in the range of high concentration of $\mathrm{H}_{2} \mathrm{O}_{2}$ which corresponds to $\mathrm{H}_{2} \mathrm{O}_{2}$ concentrations in the cancer cells investigated in our work. Fast dynamic redox regulation in this region of the S-type regulation curve is likely to allow cancer cells to maintain high level of endogenous ROS and overcome oxidative stress.

Our findings show that ROS, H2O2, NRF2 status and localisation are intricately linked. The observed connection between the ROS and NRF2 pathways might provide a basis for the cellular specificity of differential proliferative potentials and behaviours. This connection is supported by the use of experimental data, in conjunction with experimental data regarding oxidative stress responses and the NRF2-KEAP1 pathway by others (Chorley et al., 2012; Malhotra et al 2010; Yamamoto et al., 2006) to mathematically model oxidative stress. The model takes into consideration the major components that interdependently feed in and out of the NRF2-centred network to sequester or produce ROS. This minimal integrative model of cellular oxidative stress responses due to ROS may perhaps inform proliferation behaviour and its reconciliation with existing knowledge of the NRF2 signalling system. Our experimental results indicate that cells subjected to oxidative signals are directed to execute cellular processes such as proliferation up to a critical threshold. This is consistent and in 
agreement with other experimental findings (Alexis, et al., 2005; Erin et al., 2012). The kinetic model allowed us to analyse the contribution of a negative feedback transcriptional regulation of the antioxidative enzyme defense systems by the NRF2-KEAP1 response signalling. This suggestion is further strengthened by the observation that NRF2 can autoregulate its transcription (Kwak et al., 2002) and that the transcriptional level of the NRF2 gene acts as another important regulatory point to define cellular NRF2 levels (Suzuki et al., 2013).

While we are not able to explain all aspects of the observed cellular responses to ROS the combined experimental and theoretical systems do shed light on critical features of the antioxidant pathway and the mechanisms of ovarian cancer cell adaptation to ROS. This systems biology approach provides a useful framework to better understand the role of ROS in oxidative stress and in influencing the proliferative behaviour of cells, and potentially other cell behaviours. Taking into cognisance the existing gaps, future refinements to this approach could lead to a tool to evaluate, predict and manage ROS and so inform therapeutic strategies.

\section{Conflicts of Interest}

The authors declare no conflict of interest.

\section{Acknowledgments}

This work was supported by grants from The Northwoods Trust, Breakthrough Breast Cancer and Scottish Funding Council (SRDG), and personal support to AG from Scottish Informatics and Computer Science Alliance (SICSA). 


\section{Reference}

Adimora, N. J., Jones, D. P., \& Kemp, M. L., 2010. A model of redox kinetics implicates the thiol proteome in cellular hydrogen peroxide responses. Antioxidants \& redox signaling 13, $731-43$.

Baird L, Llères D, Swift S, Dinkova-Kostova AT., 2013. Regulatory flexibility in the Nrf2mediated stress response is conferred by conformational cycling of the Keap1-Nrf2 protein complex. Proc Natl Acad Sci U S A. 110, 15259-64.

Benhar M, Dalyot I, Engelberg D, Levitzki A., 2001. Enhanced ROS production in oncogenically transformed cells potentiates c-Jun N-terminal kinase and p38 mitogenactivated protein kinase activation and sensitization to genotoxic stress. Mol Cell Biol. 21, 6913-26. 
Boutten, A., Goven, D., Artaud-Macari, E., Boczkowski, J., \& Bonay, M., 2011. NRF2 targeting: a promising therapeutic strategy in chronic obstructive pulmonary disease. Trends in molecular medicine, 17, 363-71.

Chaiswing L, Zhong W, Oberley TD., 2011. Distinct redox profiles of selected human prostate carcinoma cell lines: implications for rational design of redox therapy. Cancers (Basel). 3, 3557-84.

Chowdhry S, Zhang Y, McMahon M, Sutherland C, Cuadrado A, Hayes JD., 2013. Nrf2 is controlled by two distinct $\beta$-TrCP recognition motifs in its Neh6 domain, one of which can be modulated by GSK-3 activity. Oncogene. 32, 3765-81.

Cohen M, Vecsler M, Liberzon A, Noach M, Zlotorynski E, Tzur A., 2013. Unbiased transcriptome signature of in vivo cell proliferation reveals pro- and antiproliferative gene networks. Cell Cycle. 12, 2992-3000.

D'Autréaux B, Toledano MB., 2007. ROS as signalling molecules: mechanisms that generate specificity in ROS homeostasis. Nat Rev Mol Cell Biol. 8, 813-24.

Gao X, Liu Y, Deeb D, Liu P, Liu A, Arbab AS, Gautam SC., 2013. ROS mediate proapoptotic and antisurvival activity of oleanane triterpenoid CDDO-Me in ovarian cancer cells. Anticancer Res. 33, 215-21.

Hempel N, Ye H, Abessi B, Mian B, Melendez JA., 2009. Altered redox status accompanies progression to metastatic human bladder cancer. Free Radic Biol Med. 46, 42-50.

Hlavatá L, Aguilaniu H, Pichová A, Nyström T., 2003. The oncogenic RAS2(val19) mutation locks respiration, independently of PKA, in a mode prone to generate ROS. EMBO J. 22, 3337-45. Erratum in: EMBO J. 2003, 22, 4577. 
Ho PJ, Yen ML, Tang BC, Chen CT, Yen BL., 2013. H2O2 accumulation mediates differentiation capacity alteration, but not proliferative decline, in senescent human fetal mesenchymal stem cells. Antioxid Redox Signal. 18, 1895-905.

Hole PS, Pearn L, Tonks AJ, James PE, Burnett AK, Darley RL, Tonks A., 2010. Rasinduced reactive oxygen species promote growth factor-independent proliferation in human CD34+ hematopoietic progenitor cells. Blood. 115, 238-46.

Homma S, Ishii Y, Morishima Y, Yamadori T, Matsuno Y, Haraguchi N, Kikuchi N, Satoh H, Sakamoto T, Hizawa N, Itoh K, Yamamoto M., 2009. Nrf2 enhances cell proliferation and resistance to anticancer drugs in human lung cancer. Clin Cancer Res. 15, 3423-32.

Hu Y, Rosen DG, Zhou Y, Feng L, Yang G, Liu J, Huang P., 2005. Mitochondrial manganese-superoxide dismutase expression in ovarian cancer: role in cell proliferation and response to oxidative stress. J Biol Chem. 25, 39485-92.

Itoh K, Wakabayashi N, Katoh Y, Ishii T, O'Connor T, Yamamoto M., 2003. Keap1 regulates both cytoplasmic-nuclear shuttling and degradation of Nrf2 in response to electrophiles. Genes Cells. 8, 379-91.

Jain AK, Bloom DA, Jaiswal AK., 2005. Nuclear import and export signals in control of Nrf2. J Biol Chem. 12, 29158-68. 
Kang MI, Kobayashi A, Wakabayashi N, Kim SG, Yamamoto M., 2004. Scaffolding of Keap1 to the actin cytoskeleton controls the function of Nrf2 as key regulator of cytoprotective phase 2 genes. Proc Natl Acad Sci U S A. 101, 2046-51.

Kaspar JW, Niture SK, Jaiswal AK., 2009. Nrf2:INrf2 (Keap1) signaling in oxidative stress. Free Radic Biol Med. 47, 1304-9.

Kietzmann T., 2010. Intracellular redox compartments: mechanisms and significances. Antioxid Redox Signal. 13, 395-8.

Kwak MK, Itoh K, Yamamoto M, Kensler TW., 2002. Enhanced expression of the transcription factor Nrf2 by cancer chemopreventive agents: role of antioxidant response element-like sequences in the nrf2 promoter. Mol Cell Biol. 22, 2883-92.

Laurent A, Nicco C, Chéreau C, Goulvestre C, Alexandre J, Alves A, Lévy E, Goldwasser F, Panis Y, Soubrane O, Weill B, Batteux F., 2005. Controlling tumor growth by modulating endogenous production of reactive oxygen species. Cancer Res. 65, 948-56.

Li, W., Yu, S., Liu, T., Kim, J.-H., Blank, V., Li, H., \& Kong, A.-N. T., 2008. Heterodimerization with small Maf proteins enhances nuclear retention of NRF2 via masking the NESzip motif. Biochimica et biophysica acta, 1783, 1847-56.

Lister A, Nedjadi T, Kitteringham NR, Campbell F, Costello E, Lloyd B, Copple IM, Williams S, Owen A, Neoptolemos JP, Goldring CE, Park BK., 2011. Nrf2 is overexpressed in pancreatic cancer: implications for cell proliferation and therapy. Mol Cancer 10, 37. 
Liu L, Xie H, Chen X, Shi W, Xiao X, Lei D, Li J., 2012. Differential response of normal human epidermal keratinocytes and $\mathrm{HaCaT}$ cells to hydrogen peroxide-induced oxidative stress. Clin Exp Dermatol. 37, 772-80.

Lo, S.-C., Li, X., Henzl, M. T., Beamer, L. J., \& Hannink, M., 2006. Structure of the Keap1:NRF2 interface provides mechanistic insight into NRF2 signaling. The EMBO journal, 25, 3605-17.

Malhotra D, Portales-Casamar E, Singh A, Srivastava S, Arenillas D, Happel C, Shyr C, Wakabayashi N, Kensler TW, Wasserman WW, Biswal S., 2010. Global mapping of binding sites for Nrf2 identifies novel targets in cell survival response through ChIP-Seq profiling and network analysis. Nucleic Acids Res. 38, 5718-34.

Manandhar S, Lee S, Kwak MK. Effect of stable inhibition of NRF2 on doxorubicin sensitivity in human ovarian carcinoma OV90 cells. Arch Pharm Res. 33, 717-26.

Martinez EE, Anderson PD, Logan M, Abdulkadir SA., 2012. Antioxidant treatment promotes prostate epithelial proliferation in Nkx3.1 mutant mice. PLoS One. 7, 46792.

McMahon M, Thomas N, Itoh K, Yamamoto M, Hayes JD., 2004. Redox-regulated turnover of Nrf2 is determined by at least two separate protein domains, the redox-sensitive Neh2 degron and the redox-insensitive Neh6 degron. J Biol Chem. 279, 31556-67.

Ngô C, Chéreau C, Nicco C, Weill B, Chapron C, Batteux F., 2009. Reactive oxygen species controls endometriosis progression. Am J Pathol. 175, 225-34.

Niture SK, Jain AK, Shelton PM, Jaiswal AK., 2011. Src subfamily kinases regulate nuclear export and degradation of transcription factor Nrf2 to switch off Nrf2-mediated antioxidant activation of cytoprotective gene expression. J Biol Chem. 286, 28821-32. 
Niture SK, Jaiswal AK., 2012. Nrf2 protein up-regulates antiapoptotic protein Bcl-2 and prevents cellular apoptosis. J Biol Chem. 287, 9873-86.

Niture SK, Jaiswal AK., 2013. Nrf2-induced antiapoptotic Bcl-xL protein enhances cell survival and drug resistance. Free Radic Biol Med. 57, 119-31.

Niture SK, Khatri R, Jaiswal AK., 2013. Regulation of Nrf2-an update. Free Radic Biol Med. $66,36-44$

Ohta T, Iijima K, Miyamoto M, Nakahara I, Tanaka H, Ohtsuji M, Suzuki T, Kobayashi A, Yokota J, Sakiyama T, Shibata T, Yamamoto M, Hirohashi S., 2008. Loss of Keap1 function activates Nrf2 and provides advantages for lung cancer cell growth. Cancer Res. 68, 1303-9.

Okoh VO, Felty Q, Parkash J, Poppiti R, Roy D., 2013. Reactive oxygen species via redox signaling to PI3K/AKT pathway contribute to the malignant growth of 4-hydroxy estradioltransformed mammary epithelial cells. PLoS One. 8, e54206.

Qutub, A. A., \& Popel, A. S., 2008. Reactive oxygen species regulate hypoxia-inducible factor 1alpha differentially in cancer and ischemia. Molecular and cellular biology, 28, 510619.

Raha D, Wilson TR, Peng J, Peterson D, Yue P, Evangelista M, Wilson C, Merchant M, Settleman J., 2014. The cancer stem cell marker aldehyde dehydrogenase is required to maintain a drug-tolerant tumor cell subpopulation. Cancer Res. 74, 3579-90. 
Reddy NM, Kleeberger SR, Yamamoto M, Kensler TW, Scollick C, Biswal S, Reddy SP., 2007. Genetic dissection of the Nrf2-dependent redox signaling-regulated transcriptional programs of cell proliferation and cytoprotection. Physiol Genomics. 32, 74-81.

Ruiz-Ginés JA, López-Ongil S, González-Rubio M, González-Santiago L, Rodríguez-Puyol M, Rodríguez-Puyol D., 2000. Reactive oxygen species induce proliferation of bovine aortic endothelial cells. J Cardiovasc Pharmacol. 35, 109-13.

Sceneay J, Liu MC, Chen A, Wong CS, Bowtell DD, Möller A., 2013. The antioxidant Nacetylcysteine prevents HIF-1 stabilization under hypoxia in vitro but does not affect tumorigenesis in multiple breast cancer models in vivo. PLoS One. 8, e66388.

Shimojo Y, Akimoto M, Hisanaga T, Tanaka T, Tajima Y, Honma Y, Takenaga K., 2013. Attenuation of reactive oxygen species by antioxidants suppresses hypoxia-induced epithelial-mesenchymal transition and metastasis of pancreatic cancer cells. Clin Exp Metastasis. 30, 143-54.

Singh A, Boldin-Adamsky S, Thimmulappa RK, Rath SK, Ashush H, Coulter J, Blackford A, Goodman SN, Bunz F, Watson WH, Gabrielson E, Feinstein E, Biswal S., 2008. RNAimediated silencing of nuclear factor erythroid-2-related factor 2 gene expression in non-small cell lung cancer inhibits tumor growth and increases efficacy of chemotherapy. Cancer Res. $68,7975-84$

Soini Y, Näpänkangas U, Järvinen K, Kaarteenaho-Wiik R, Pääkkö P, Kinnula VL., 2001. Expression of gamma-glutamyl cysteine synthetase in nonsmall cell lung carcinoma. Cancer. 92, 2911-9. 
Sokolovski, S. G., Zolotovskaya, S. A., Goltsov, A., Pourreyron, C., South, A. P., \& Rafailov, E. U., 2013. Infrared laser pulse triggers increased singlet oxygen production in tumour cells. Scientific reports, 3, 3484 .

Song MS, Carracedo A, Salmena L, Song SJ, Egia A, Malumbres M, Pandolfi PP., 2011. Nuclear PTEN regulates the APC-CDH1 tumor-suppressive complex in a phosphataseindependent manner. Cell. 144, 187-99.

Sun Z, Wu T, Zhao F, Lau A, Birch CM, Zhang DD., 2011. KPNA6 (Importin \{alpha\}7)mediated nuclear import of Keap1 represses the Nrf2-dependent antioxidant response. Mol Cell Biol. 31, 1800-11.

Suzuki T, Shibata T, Takaya K, Shiraishi K, Kohno T, Kunitoh H, Tsuta K, Furuta K, Goto K, Hosoda F, Sakamoto H, Motohashi H, Yamamoto M., 2013. Regulatory nexus of synthesis and degradation deciphers cellular Nrf2 expression levels. Mol Cell Biol. 33, 240212.

Theodore M, Kawai Y, Yang J, Kleshchenko Y, Reddy SP, Villalta F, Arinze IJ., 2008. Multiple nuclear localization signals function in the nuclear import of the transcription factor Nrf2. J Biol Chem. 283, 8984-94.

Velarde V, de la Cerda PM, Duarte C, Arancibia F, Abbott E, González A, Moreno F, Jaffa AA., 2004. Role of reactive oxygen species in bradykinin-induced proliferation of vascular smooth muscle cells. Biol Res. 37, 419-30.

Wakabayashi, N., Dinkova-Kostova, A. T., Holtzclaw, W. D., Kang, M.-I., Kobayashi, A., Yamamoto, M., Talalay, P., 2004. Protection against electrophile and oxidant stress by 
induction of the phase 2 response: fate of cysteines of the Keap 1 sensor modified by inducers. Proc. Natl. Acad. Sci. USA, 101, 2040-5.

Wang J, Lin D, Peng H, Huang Y, Huang J, Gu J., 2013. Cancer-derived immunoglobulin G promotes tumor cell growth and proliferation through inducing production of reactive oxygen species. Cell Death Dis. 4, e945.

Wang XJ, Sun Z, Villeneuve NF, Zhang S, Zhao F, Li Y, Chen W, Yi X, Zheng W, Wondrak GT, Wong PK, Zhang DD., 2008. Nrf2 enhances resistance of cancer cells to chemotherapeutic drugs, the dark side of Nrf2. Carcinogenesis. 29, 1235-43.

Yamamoto, T., Kyo, M., Kamiya, T., Tanaka, T., Engel, J. D., Motohashi, H., \& Yamamoto, M., 2006. Predictive base substitution rules that determine the binding and transcriptional specificity of Maf recognition elements. Genes to cells : devoted to molecular \& cellular mechanisms, 11, 575-91.

Zhang L, Wang N, Zhou S, Ye W, Jing G, Zhang M., 2012. Propofol induces proliferation and invasion of gallbladder cancer cells through activation of Nrf2. J Exp Clin Cancer Res. 31,66 . 


\section{FIGURE Legends:}

Figure 1: Model of NRF2 signalling which involves the following processes: (1) KEAP1dependent degradation of NRF2 in cytoplasm; (2) oxidation of KEAP1 by $\mathrm{H}_{2} \mathrm{O}_{2}$ resulting in dissociation of NRF2-KEAP1 complex; (3) NRF2 trafficking into nucleus; (4) formation of activation transcription factor, NRF2-MAF heterodimer; (5 and 6) binding of transcription factor NRF2-MAF with ARE sites and translation of antioxidant proteins Px; (7) formation of the repression transcription factor, MAF-MAF homodimer, and its binding with ARE sites; (8) reduction of KEAP1 by Trx; (9) redox antioxidative enzymatic system degrading $\mathrm{H}_{2} \mathrm{O}_{2}$; (10) diffusion of $\mathrm{H}_{2} \mathrm{O}_{2}$ through cellular membrane; (11) catalysis of $\mathrm{GSH}$ from endogenous NAC.

Figure 2: Ovarian cancer cell lines exhibit different rates of proliferation that show agreement with constitutive ROS levels. (a) Ovarian cancer cells have distinct growth rates. For proliferation assay, cells were seeded in triplicates in 24-well plates and allowed to grow for different days as indicated. On the day of cell count, cells were trypsinized and counted using haemocytometer. Dots indicate experimental data while lines represent best-fitting of the experimental data using exponential equation. HaCaT cells-black dots and line, PEO1-red dots and line, PEO4-green dots and line, PEO6-magenta dots and line, OVCAR3-brown dots and line, OVCAR4-pink dots and line. Data are the means and standard error (bars) of $n=3$ independent experiments performed in triplicates. (b) Ovarian cancer cells show elevated but dissimilar levels of total reactive oxygen species (ROS). Cells seeded for $18 \mathrm{hrs}$ in opaque flat bottom 96-well plates were either treated with DMSO only or CELLROX®green reagent to assay for basal ROS as described in materials and methods. ROS was measured as 
fluorescence signal using 96-well plate fluorescence multiplate reader (MODULUS $^{\mathrm{TM}}$, Promega) using $485 / 520 \mathrm{~nm}$ filter set. Data are the means and standard error (bars) of experiments performed in quadruplicates. (c) Cells were seeded and treated as above and imaged under 485/520 nm filter set with a Leica DMiRe2 electronic microscope. These are representative images captured using $5 \mathrm{x}$ objective. Scale bar represents $50 \mu \mathrm{m}$.

Figure 3: NRF2 and KEAP1 protein expression is different among ovarian cancer cell lines. (a) Immunoblotting analysis of constitutive levels of total NRF2 and KEAP1 show variation among human keratinocytes and panel of ovarian cancer cell lines. Exponentially growing cells were harvested and protein lysates prepared and further processed for immunoblotting as mentioned in materials and methods using relevant antibodies (Table 1). For loading control, $\beta$-actin antibody was used. (b) Bar chart showing NRF2 and KEAP1 protein abundance in different cells expressed in nanograms (ng) by quantifying immunoblot signal intensities obtained in (a) and by utilising standard curve of immunoblot signals as established in Supplementary fig 3. The signal intensities were quantified through integrated optical densitometry measurement using Gelpro software (Version 3.1, Media Cybernetics). Data presented in all panels are the mean with standard error (bars) of $n=3$ independent experiments.

Figure 4: Normal and ovarian cancer cell lines exhibit differences in sub-cellular localisation of endogenous basal NRF2. (a) Immunoblotting following sub-cellular protein fractionation revealed nuclear protein abundance of NRF2 in most of the ovarian cancer cell lines studied. Cells grown on $60 \mathrm{~mm}$ plates were harvested and protein lysates fractionated into nuclear $(\mathrm{N})$ and cytoplasmic (C) fractions and subjected to immunoblotting using anti NRF2 antibody (table 1). (b) The immunoblot signal intensities obtained in (a) were 
subjected to semi quantitative analysis through integrated optical densitometry measurement using Gelpro software (Version 3.1, Media Cybernetics). Signal intensity from each fraction of a cell line was represented as $\%$ abundance of total signal from the two fractions (considered as $100 \%$ ). Data presented in all panels are the mean of $n=3$ independent experiments. (c) Immunofluorescent labelling of endogenous NRF2 reveals predominantly nuclear localisation in most of the ovarian cancer cell lines studied. Cells grown on poly-L lysine coated coverslips were processed for immunocytochemistry as described in materials. To immunolabel endogenous NRF2, anti NRF2 primary antibody (table 1) followed by Alexa Fluor ${ }^{\circledR}$ 488/568 conjugated goat anti-rabbit secondary antibody (green fluorescence) was used. Staining of F-Actin filaments was performed by using Alexa fluor ${ }^{\circledR} 568$ conjugated Phalloidin (Invitrogen) and capturing image with 578/600nm filter set (red fluorescence). Cytoplasmic localisation was confirmed by performing colocalisation of immunolabelled NRF2 with F-Actin using integrated features of ANDOR iQ core software (ANDOR Technologies Ltd). Scale bar indicates $10 \mu \mathrm{m}$. These are representative images taken in different field of views with 100x objective with Leica DMiRe2 electronic microscope.

Figure 5: Protein stability of endogenous NRF2 exhibits differences in ovarian cancer cell lines and is enhanced as compared to HaCat cells. (a) Immunoblotting for total NRF2 following treatment with $50 \mu \mathrm{M}$ Cycloheximide (Sigma) revealed differences in basal NRF2 protein stability among cell lines. Cells were either left untreated (0) or treated with cycloheximide for different time points indicated in minutes (min) and protein lysates processed for immunoblot analysis of total NRF2 using anti NRF2 antibody (table 1) (b) The immunoblot signal intensities obtained in (a) were subjected to semi quantitative analysis through integrated optical densitometry measurement using Gelpro software (Version 3.1, Media Cybernetics). Dots are mean signal intensities represented as a fraction of the signal 
obtained at time 0 (set as 1). Lines represent the result of the best-fitting of the experimental data by two-exponential equations. HaCaT cells - black line and points, PEO1 - red, SKOV3 - blue, PEO6 - green, OVCAR3 - brown, PEO4 - magenta and OVCAR4 - grey.

Figure 6: Ovarian cancer cells show faster but dissimilar kinetics of exogenous ROS scavenging illustrating a robust antioxidant signalling response. Time dependent $\mathrm{H}_{2} \mathrm{O}_{2}$ neutralisation assay was performed following challenge with $5 \mu \mathrm{M} \mathrm{H}_{2} \mathrm{O}_{2}$ followed by either immediately performing $\mathrm{H}_{2} \mathrm{O}_{2}$ detection assay (time 0 ) or at different time points following treatment as indicated in figure and described in materials and methods. The data obtained was normalised to represent actual Nanomolar $\mathrm{H}_{2} \mathrm{O}_{2}$ levels $(\mathrm{nM})$ established through standard curve of $\mathrm{H}_{2} \mathrm{O}_{2}$ and are the mean with standard error (bars) performed in quadruplicates for each treatment.

Figure 7: Treatment with antioxidant $\mathrm{N}$-Acetyl Cysteine or $\mathrm{ROS}$ inducing $\mathrm{H}_{2} \mathrm{O}_{2}$ causes distinctive time dependent changes in sub-cellular localization and total NRF2 levels in cell lines indicating dissimilar kinetics of antioxidant response. Time course treatment with 10mM N-Acetyl cysteine (NAC) caused disappearance of NRF2 from cytoplasm with overall reduction in total NRF2 while $\mathrm{H}_{2} \mathrm{O}_{2}$ induced its nuclear accumulation. Cells grown on poly-L lysine (Sigma-Aldrich) coated cover slips were either left untreated (time 0) or exposed to $10 \mathrm{mM}$ NAC or $100 \mu \mathrm{M} \mathrm{H}_{2} \mathrm{O}_{2}$. At indicated time points represented in minutes (min), treatments were stopped and coverslips processed for immunocytochemistry. To stain for endogenous NRF2, anti NRF2 primary antibody (table 1) followed by Alexa Fluor ${ }^{\circledR} 488 / 568$ conjugated goat anti-rabbit secondary antibody (green fluorescence) was used. Staining of FActin filaments was performed by using Alexa fluor ${ }^{\circledR} 568$ conjugated Phalloidin (Invitrogen) 
and capturing image with 578/600nm filter set (red fluorescence). Cytoplasmic localisation was confirmed by performing colocalisation of immunolabelled NRF2 with F-Actin filaments using integrated features of ANDOR iQ core software (ANDOR Technologies Ltd) while nuclear reference was provided by co-staining with 4',6-Diamidino-2-Phenylindole, Dihydrochloride (DAPI). Panels a, $d \& g$ are representative images taken with relevant filter sets and captured in different field of views with 100x objective with Leica DMiRe2 electronic microscope with scale bar representing $10 \mu \mathrm{m}$. Bar charts in panels b, c (PEO1) e, $\mathrm{f}$ $(\mathrm{HaCaT}) \& \mathrm{~h}, \mathrm{I}(\mathrm{OVCAR} 3)$ represent immunofluorescent intensity measurements of either total NRF2 immunostaining (black bars) or of individual intensities obtained from nuclear and cytoplasmic compartments (blue and red bars respectively) using integrated features of Andor IQ core software (ANDOR Technologies Ltd). Values represent mean fluorescent intensities of either single cells or nuclear and cytoplasmic fractions of at least 10 cells per slide for a treatment in different field of views and normalised to total fluorescence from untreated controls (UT) set as 100\%.

Figure 8: Scavenging basal ROS causes inhibition of proliferation in ovarian cancer cell lines but not in HaCat cells. Exponentially growing cells in normal media were either treated with media alone, with media containing 10mM ROS scavenging agent N-Acetyl Cysteine (NAC) or $20 \mu \mathrm{M}$ of the pro-oxidant $\mathrm{H}_{2} \mathrm{O}_{2}$. On the indicated days, cells were trypsinized and counted using haemocytometer. Data are the means and standard error (bars) of experiments performed in triplicates.

Figure 9: Computational results for $\mathrm{H}_{2} \mathrm{O}_{2}$ degradation kinetics in extracellular medium (black line), reduced, $\mathrm{Px}_{\mathrm{red}}$ (magenta line), oxidised $\mathrm{Px}_{\mathrm{ox}}$ (blue line), and total $\mathrm{Px}_{\text {tot }}$ (red line) 
peroxidase following addition of $5 \mu \mathrm{M} \mathrm{H}_{2} \mathrm{O}_{2}$ at time $\mathrm{t}=0$. Points - experimental data for HaCaT (black square) and OVCAR3 (black circle) cells.

Figure 10: Computational results for degradation kinetics of total (black lines), nuclear (blue lines), and cytoplasmic (red lines) NRF2 following cycloheximide treatment of HaCaT (a) and PE01 (b) cells. Points - experimental data for HaCaT (a) and PE01 (b) cells. NRF2 concentration is normalized to its basal level.

Figure 11: Computational results for total (black lines), nuclear (blue lines), and cytoplasmic (red lines) NRF2 kinetics under $100 \mu \mathrm{M} \mathrm{H}_{2} \mathrm{O}_{2}$ (a) and $10 \mathrm{mM} \mathrm{N}$-acetyl cysteine (NAC) (b) treatments. Points - experimental data for HaCaT cells. Nuclear and cytoplasmic NRF2 fractions are normalized to the total concentration.

Figure 12: The $\mathrm{Nrf2}-\mathrm{H}_{2} \mathrm{O}_{2}$ regulation curve. The theoretical dependence of total (black line) and nuclear (blue line) concentrations of $\mathrm{Nrf2}$ on endogenous level of $\mathrm{H}_{2} \mathrm{O}_{2}$. Point experimental data on total (black points) and nuclear (blue points) concentration of Nrf2 in seven cell lines (in arbitrary units). 


\begin{tabular}{|c|c|c|c|c|c|c|c|c|}
\hline \multirow{4}{*}{ 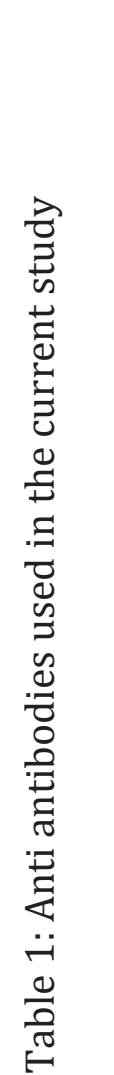 } & 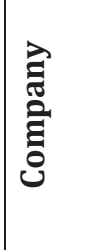 & 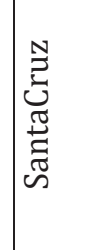 & 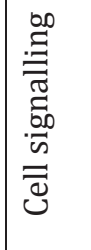 & 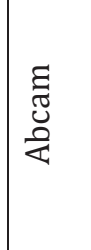 & 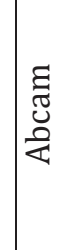 & & 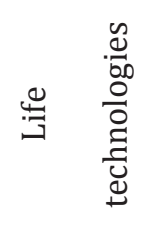 & \\
\hline & 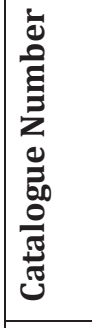 & 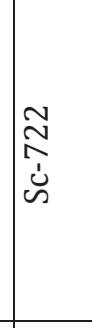 & $\mid \begin{array}{l}\infty \\
\infty \\
b \\
b\end{array}$ & 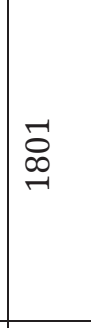 & I & & $\begin{array}{l}\text { 苛 } \\
\vec{a}\end{array}$ & \\
\hline & 㟥 & 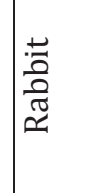 & \begin{tabular}{|l} 
蒿 \\
吾
\end{tabular} & 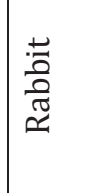 & 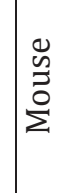 & & 莺 & \\
\hline & 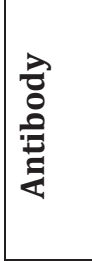 & $\begin{array}{l}\frac{\pi}{x} \\
\frac{x}{z} \\
\frac{x}{z}\end{array}$ & 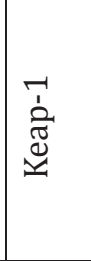 & 䭔 & 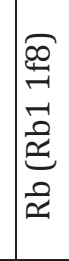 & 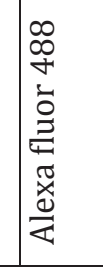 & 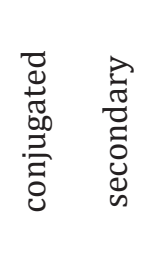 & 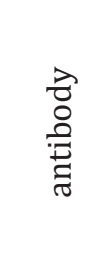 \\
\hline
\end{tabular}




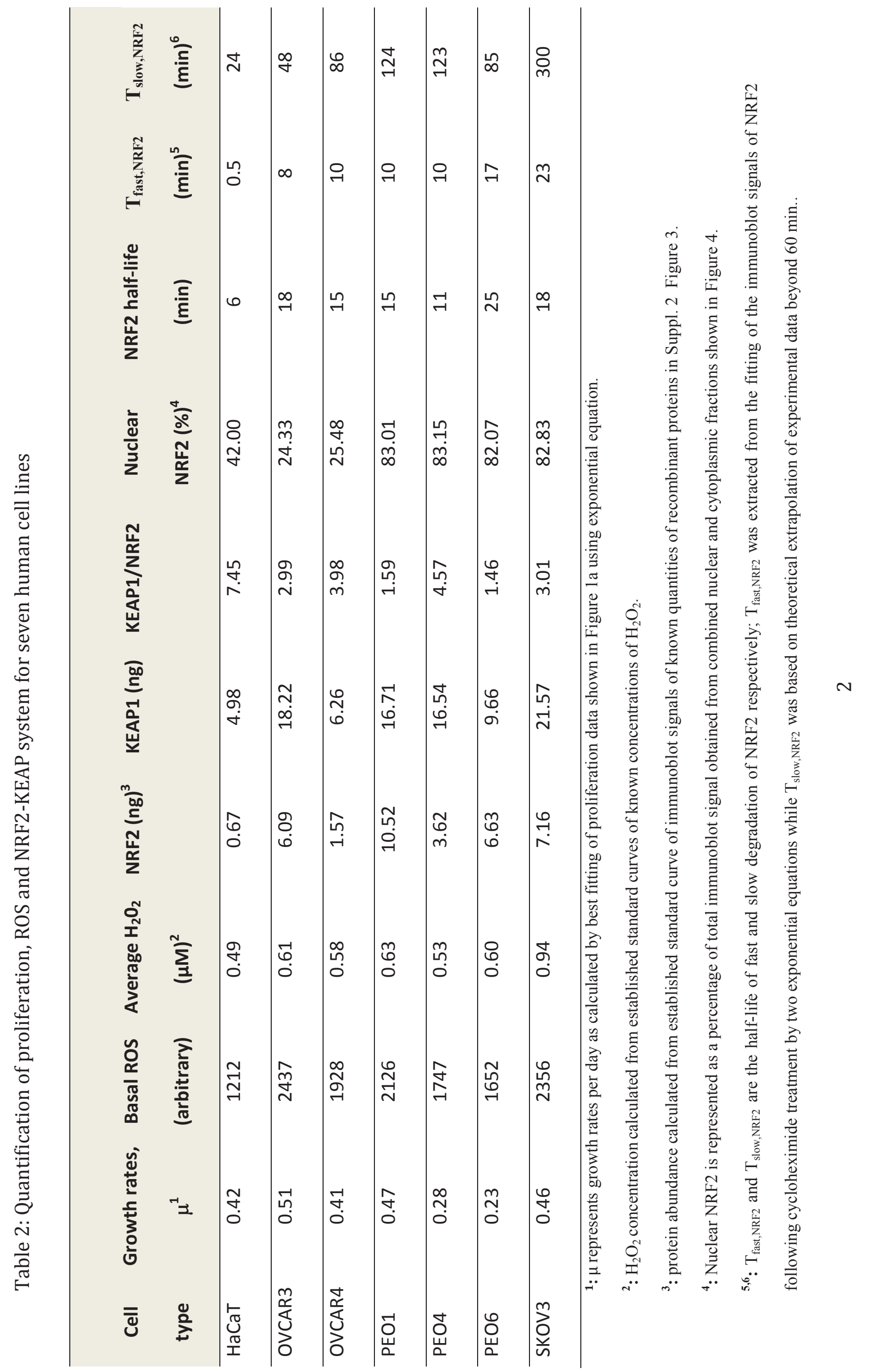




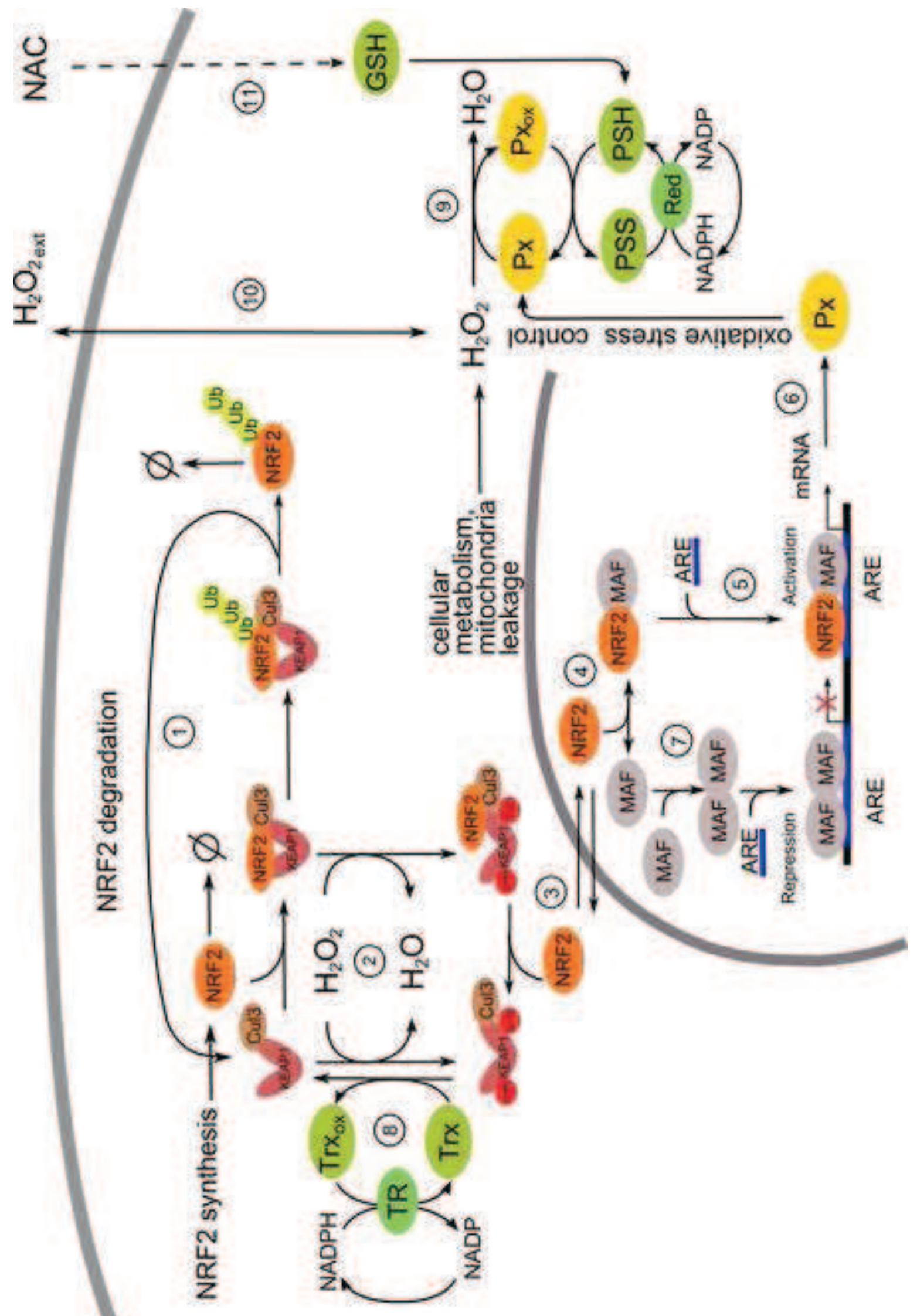

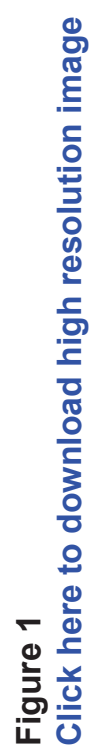



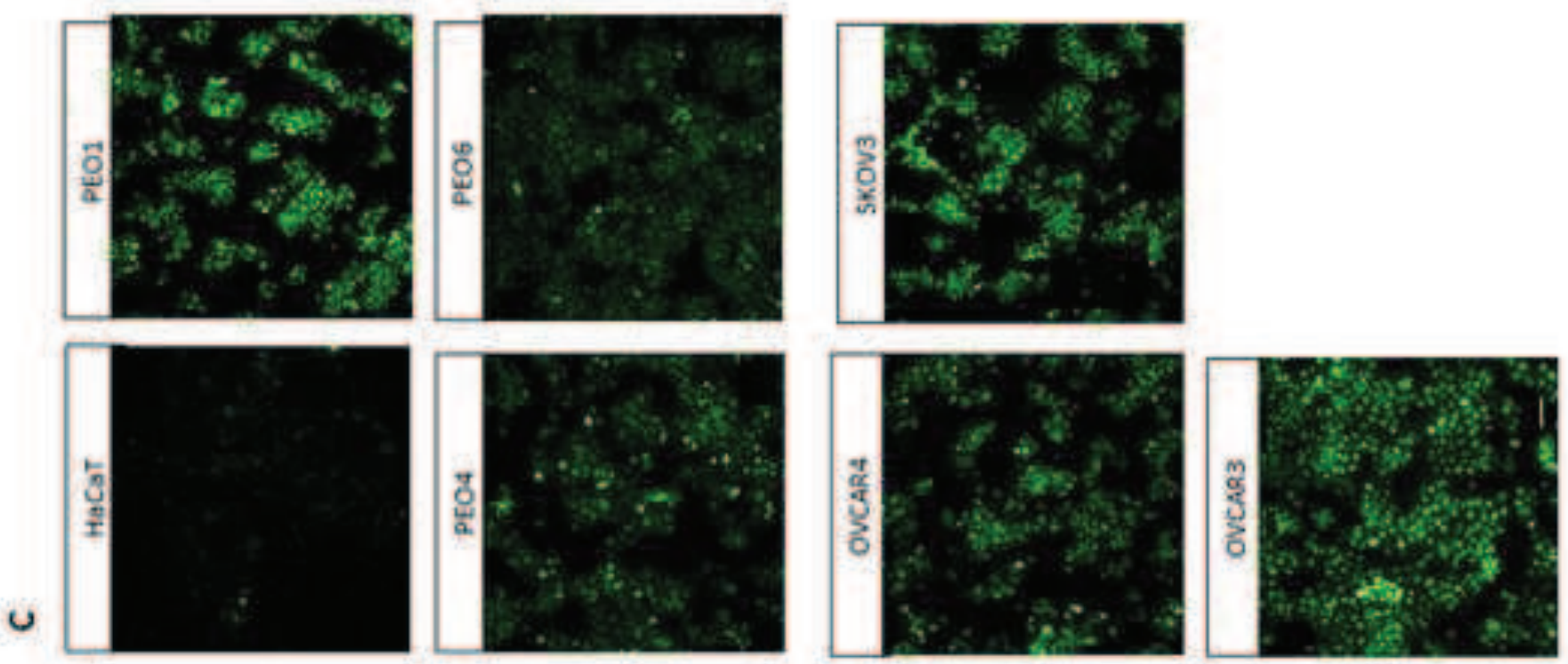

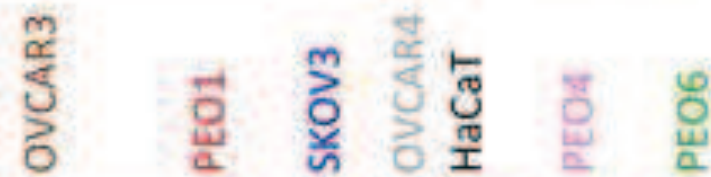

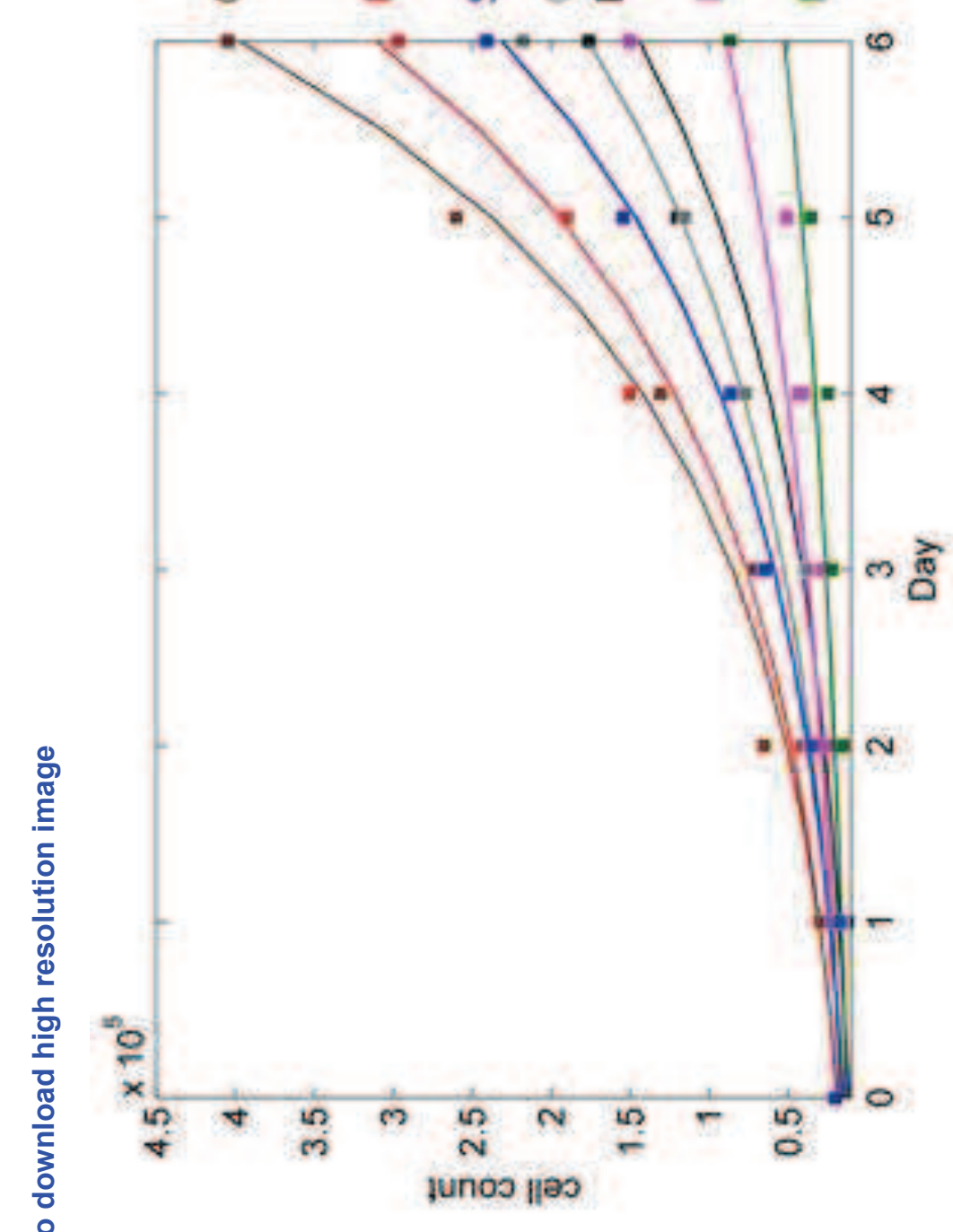

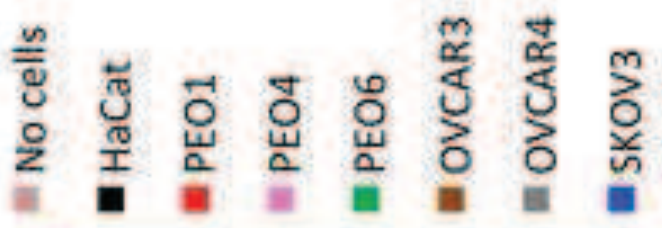
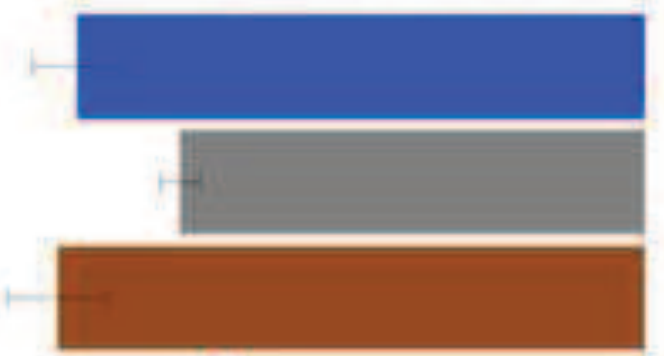

斊

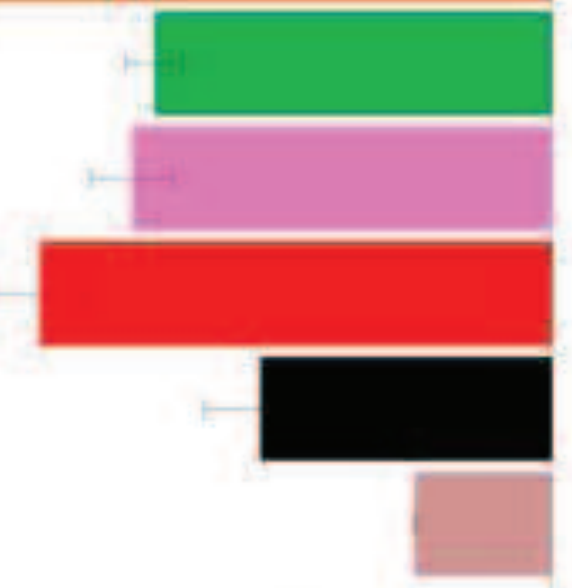

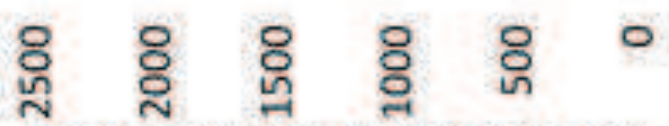

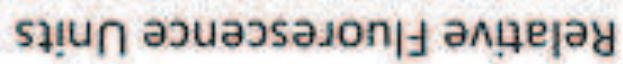



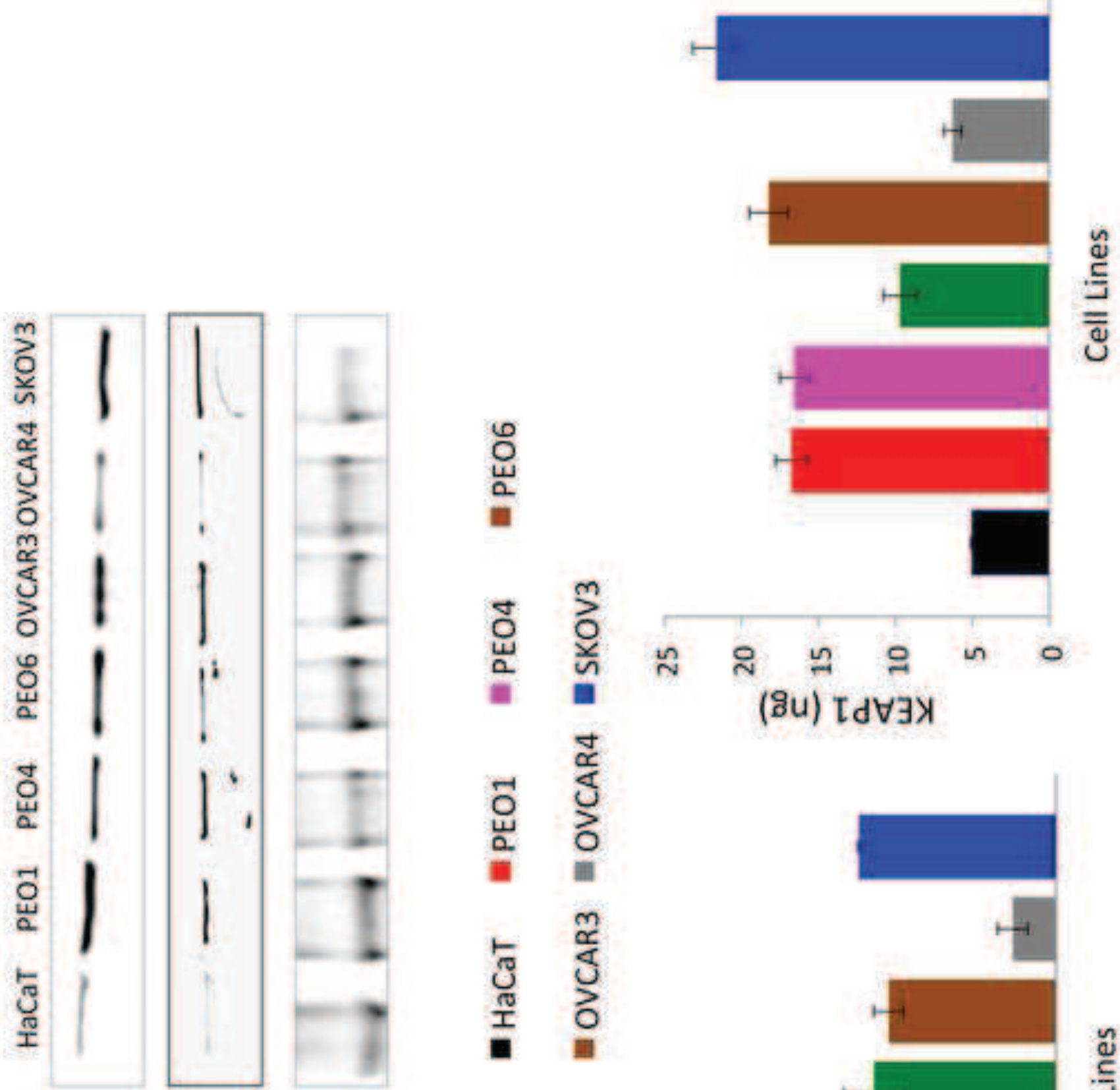

(8u) โd $\forall \exists$ त्र

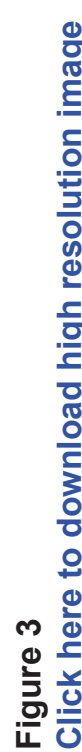

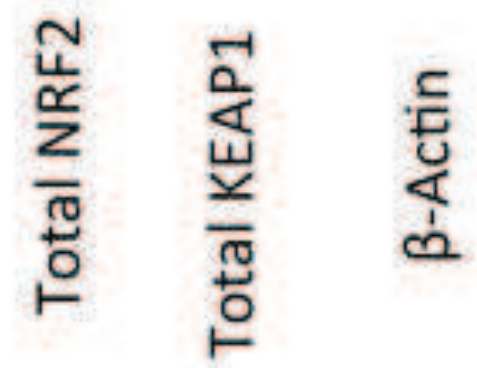

อ (ชu) Zงy

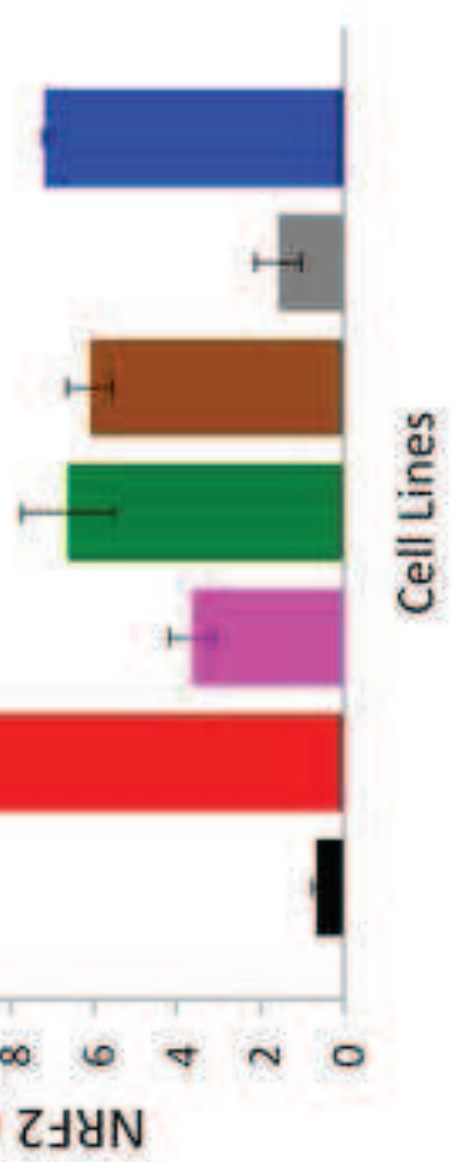




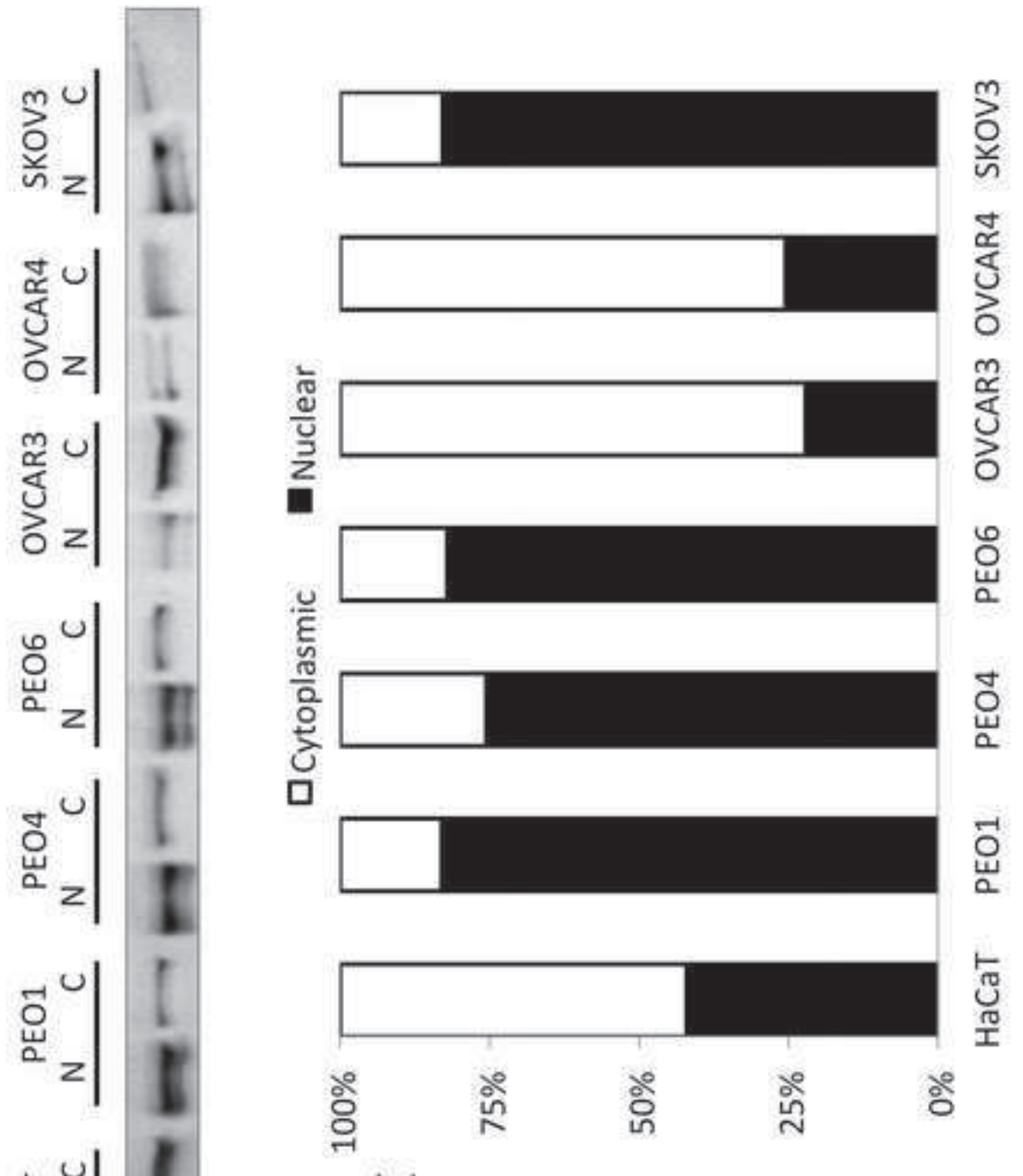

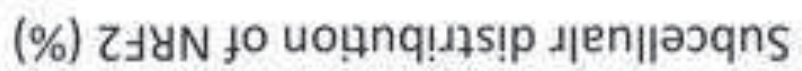

ז

م 

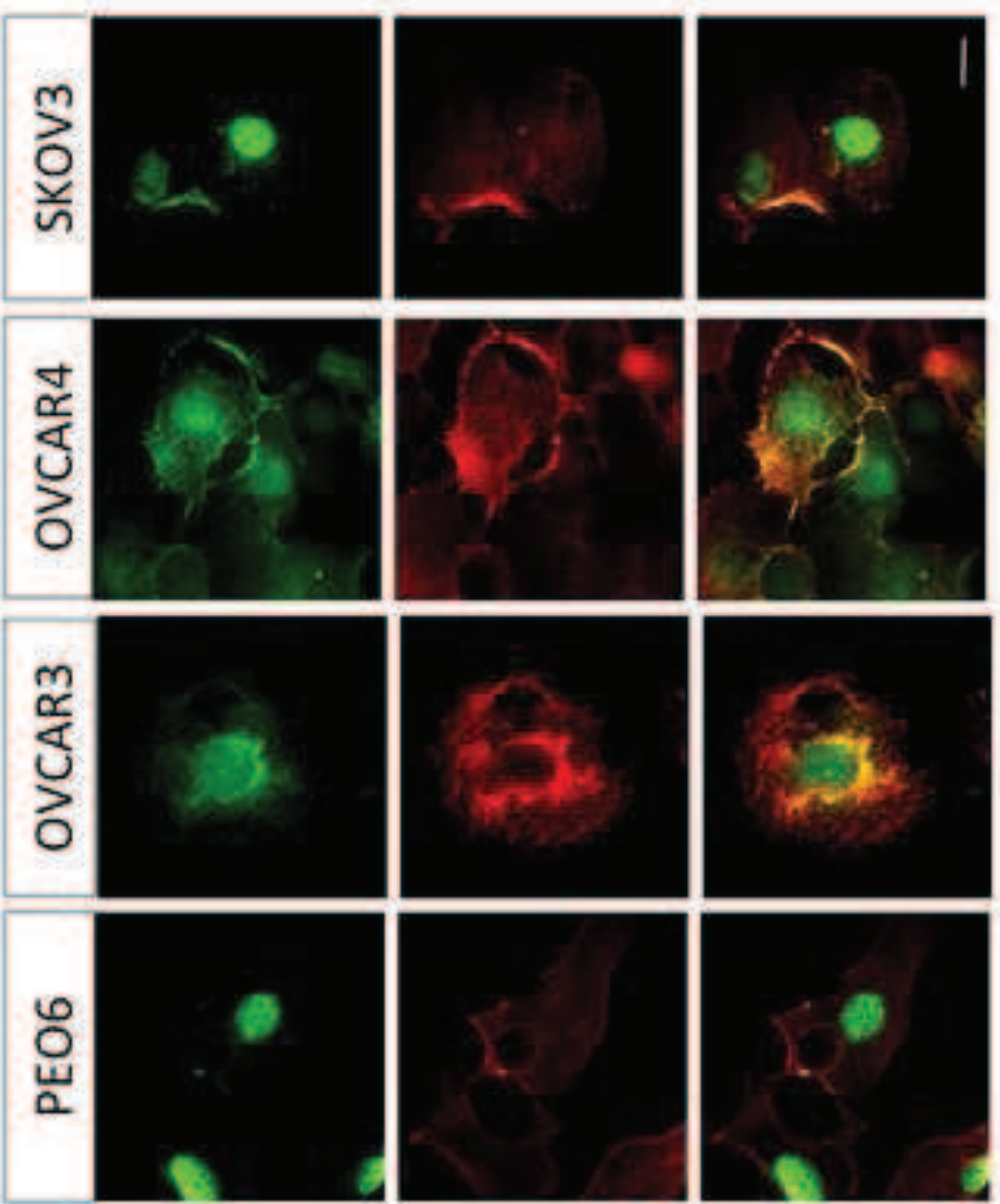

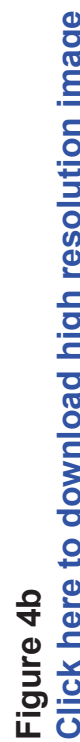
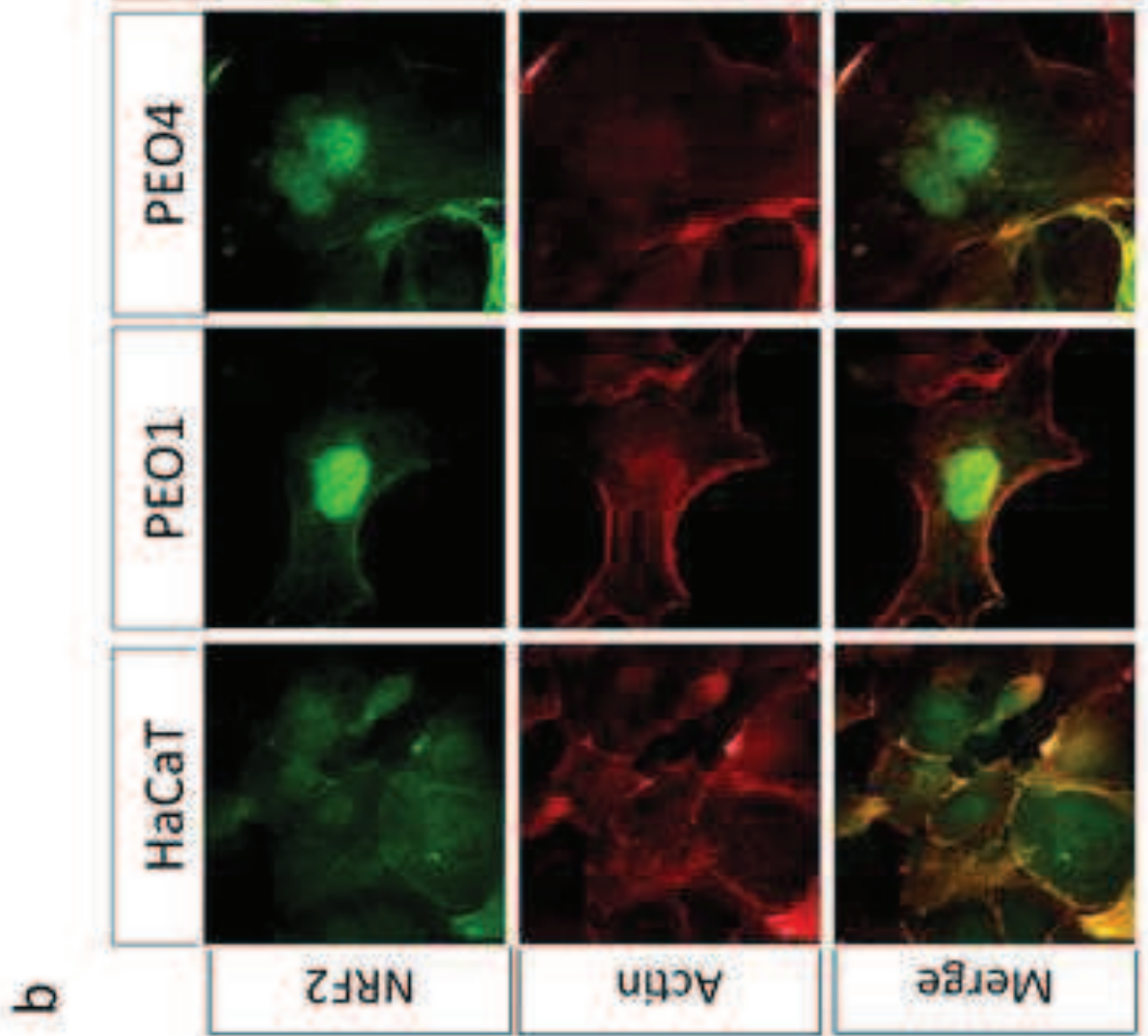


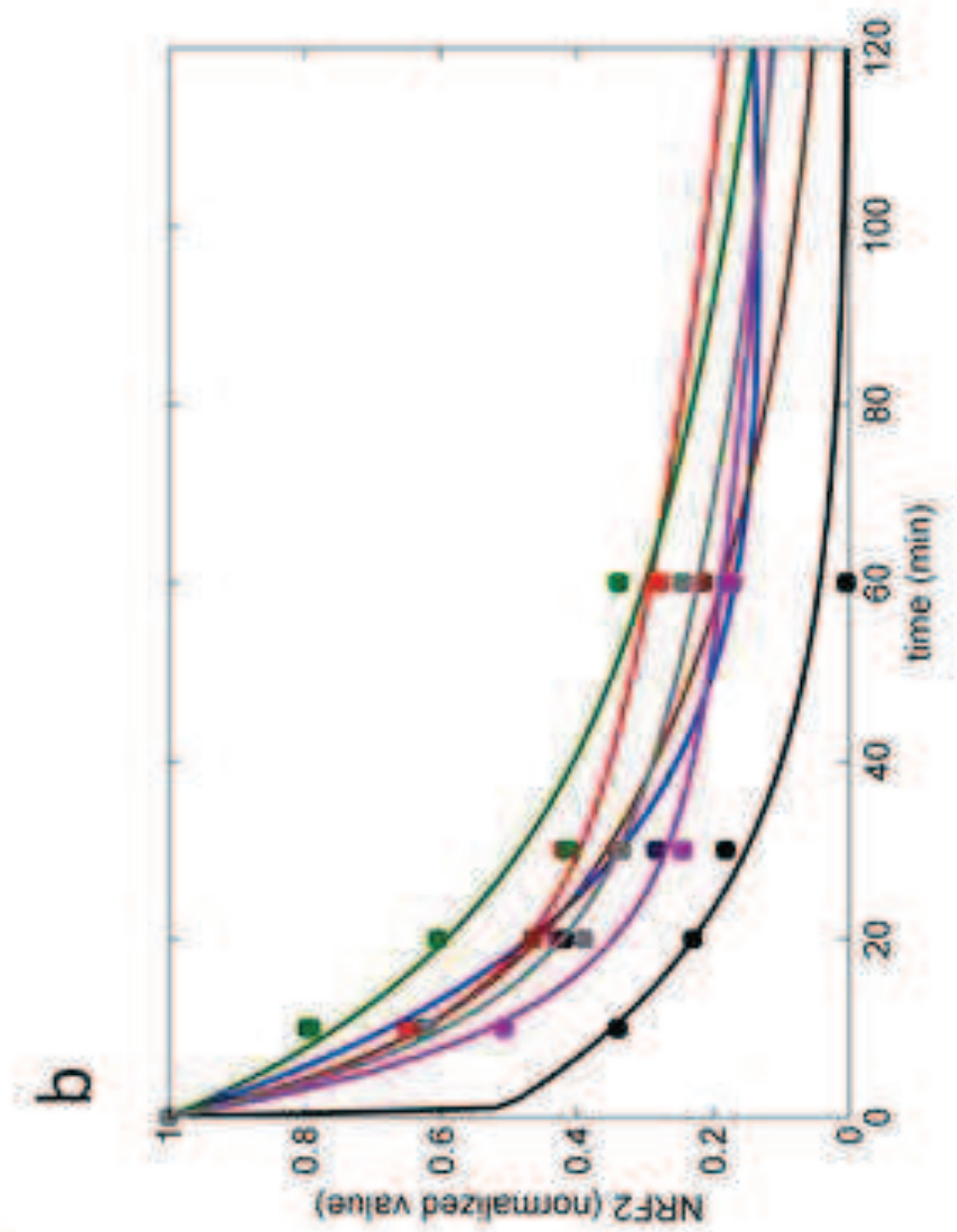

है

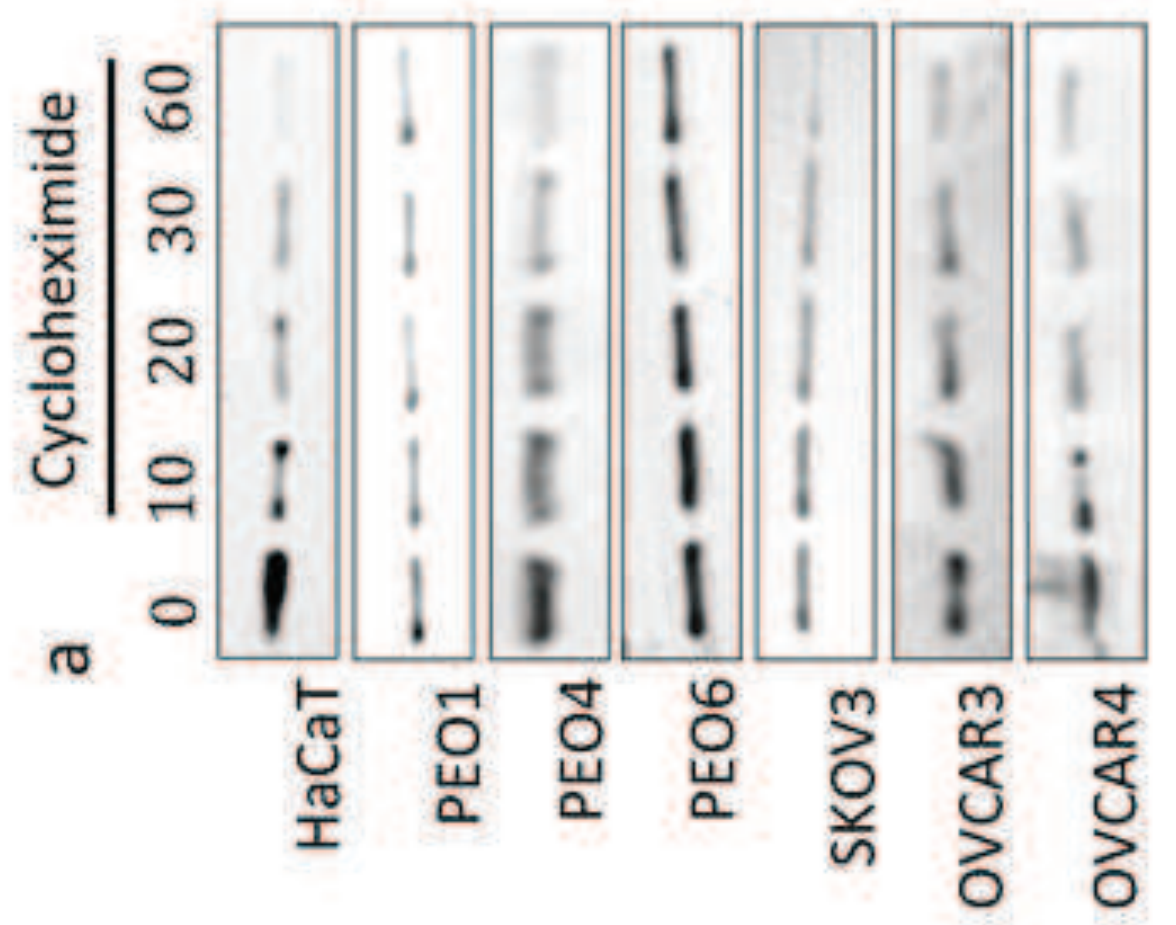

10

(1)

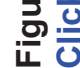




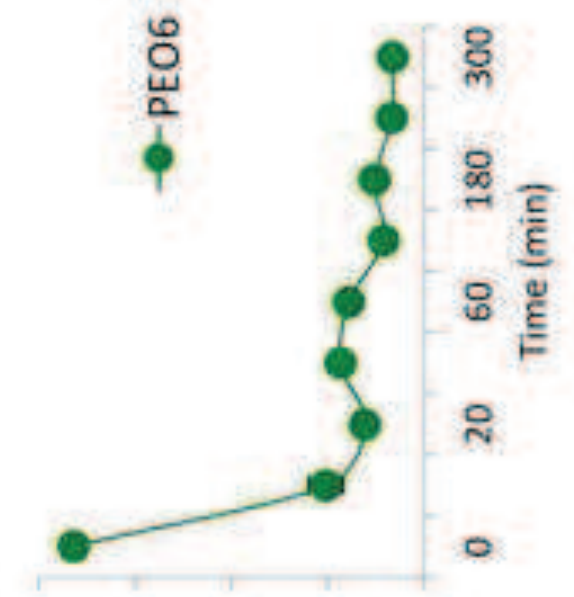

앴

(wu) $\mathrm{ZOZH}$
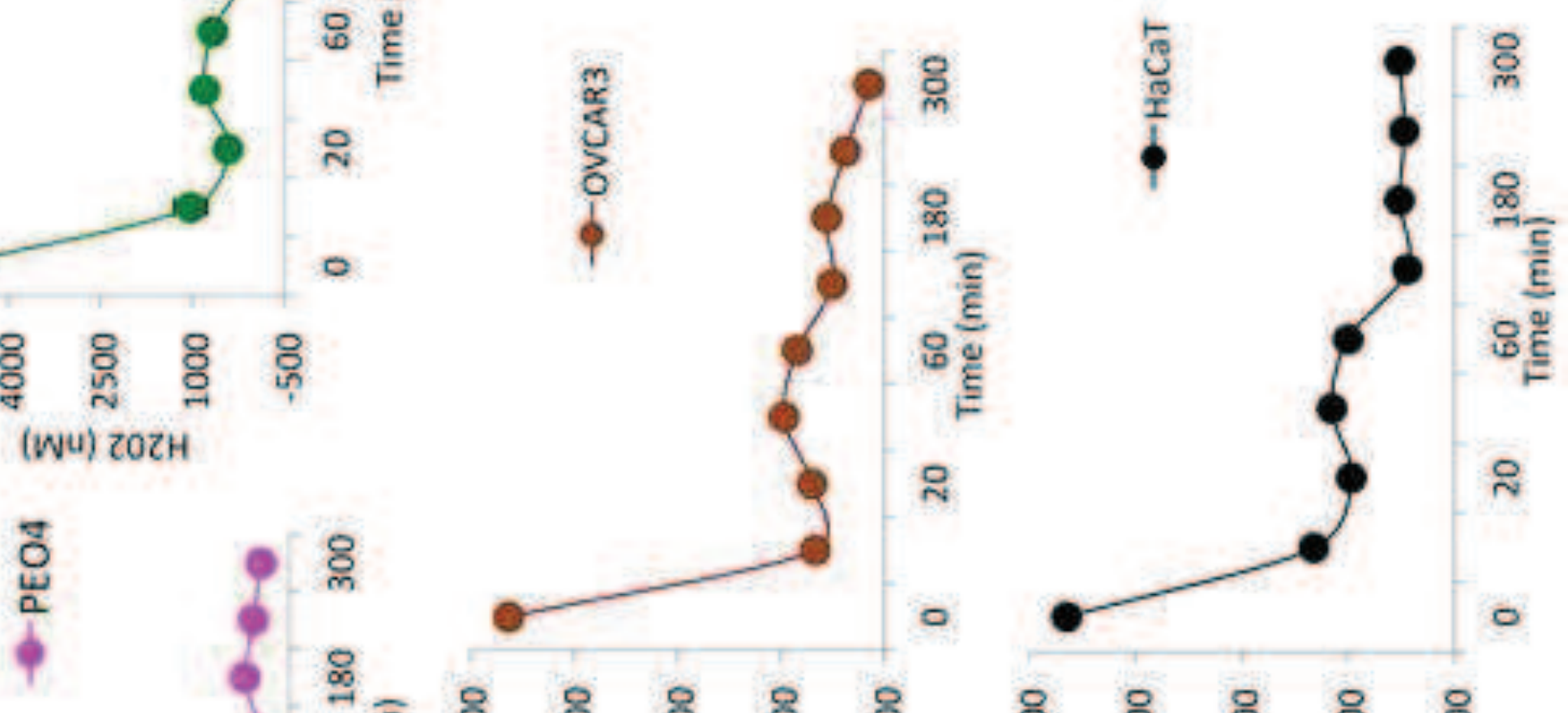

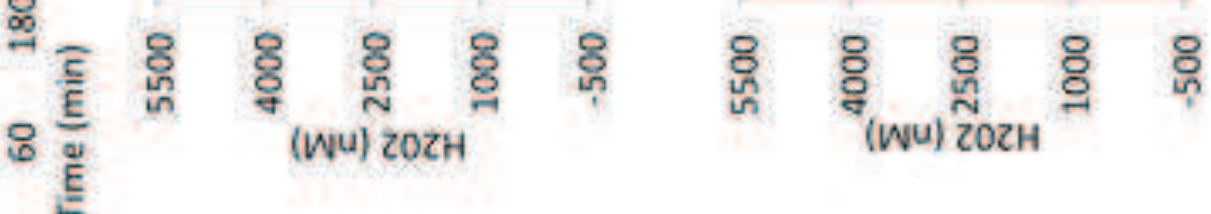

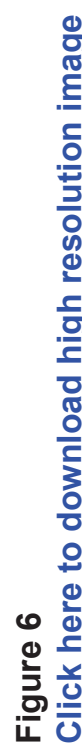

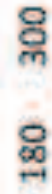

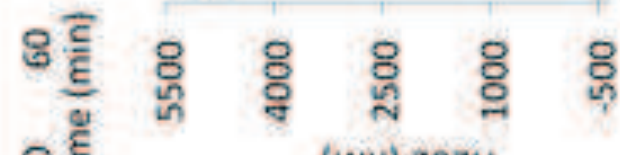

(wu) ZOZH

$\underset{\substack{8 \\ \infty}}{9}$

号 8 号 8 号

(wu) $\mathrm{ZOZH}$

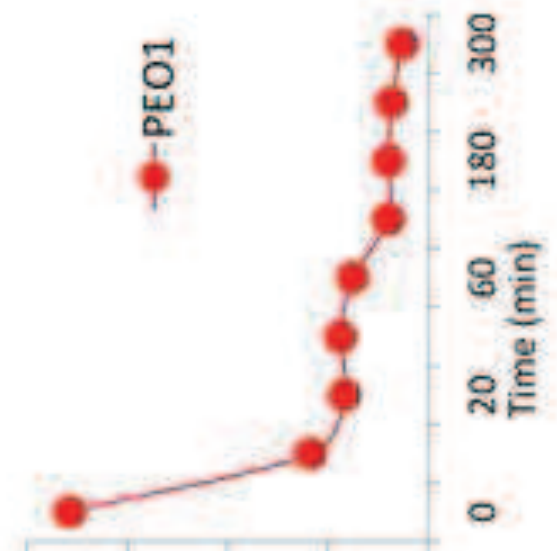

8 है

$2^{\text {हैँ }}$

$\sum_{\substack{n \\ n}}^{\substack{8 \\ m}}$

?

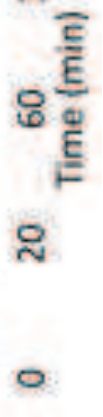

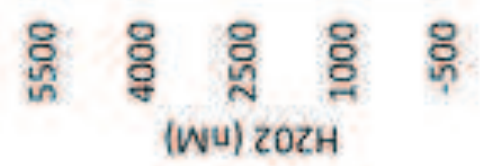




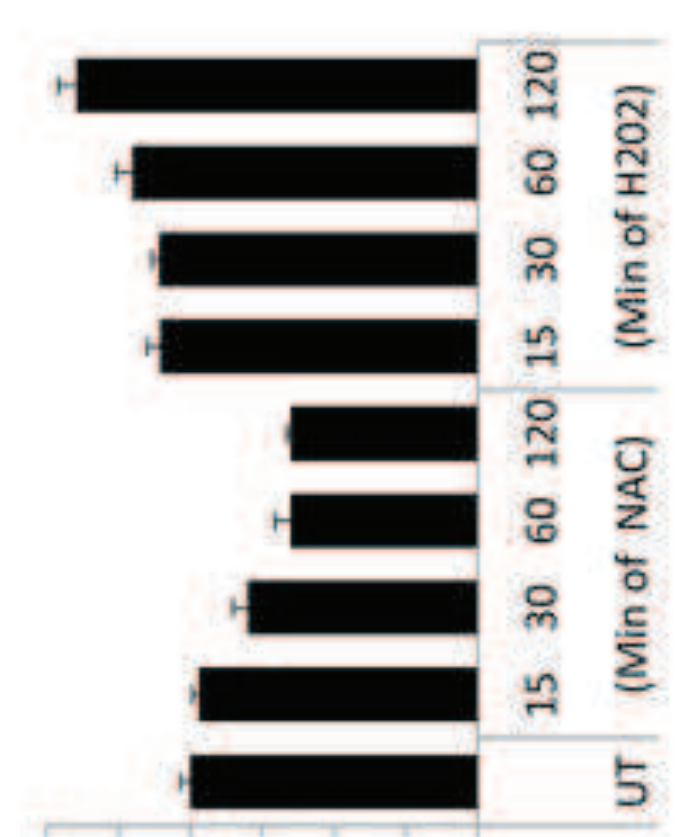

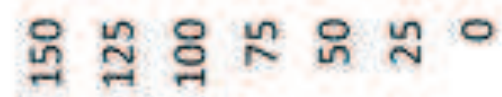

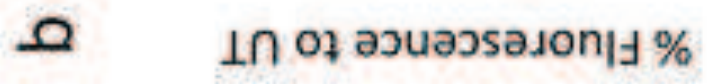

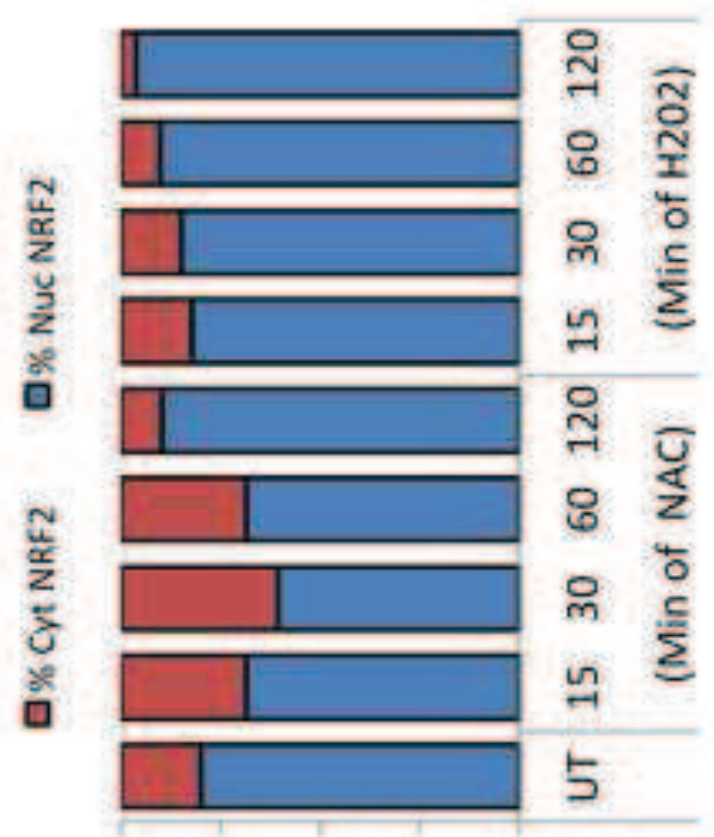

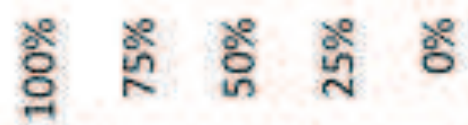

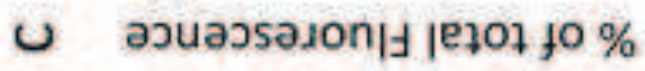

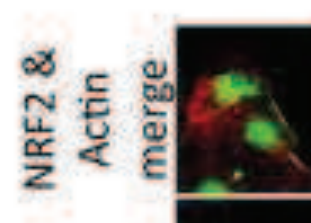

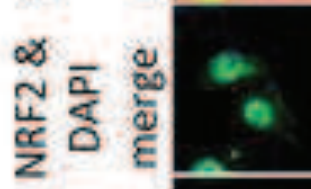

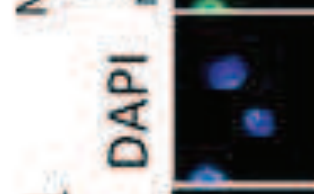

엄 至

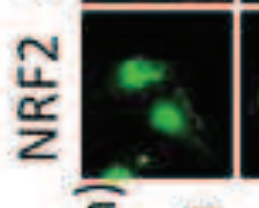

है 0

( $\stackrel{\varrho}{\models}$
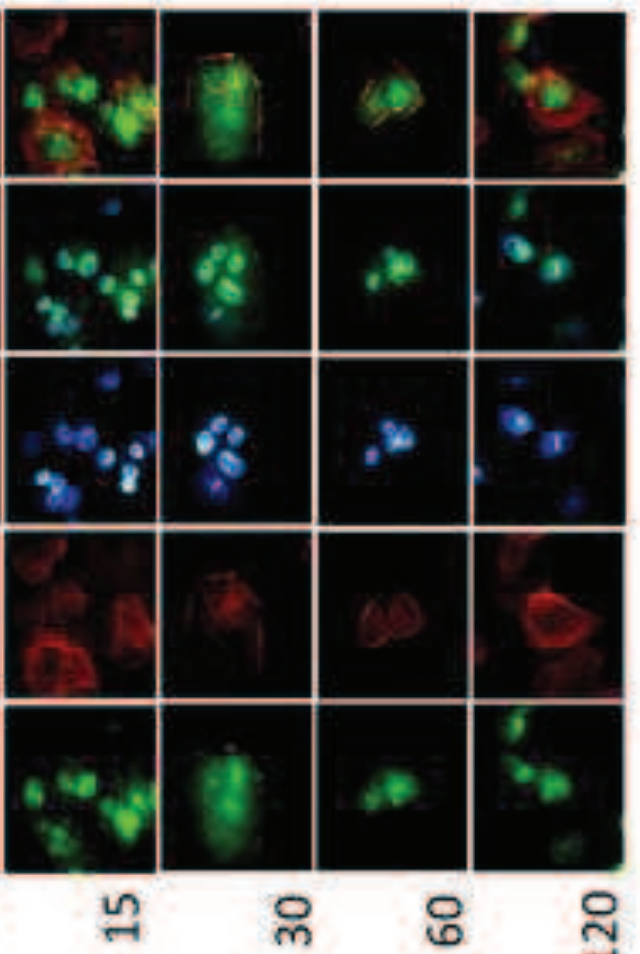

8

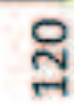

(WWot) $J \forall N$

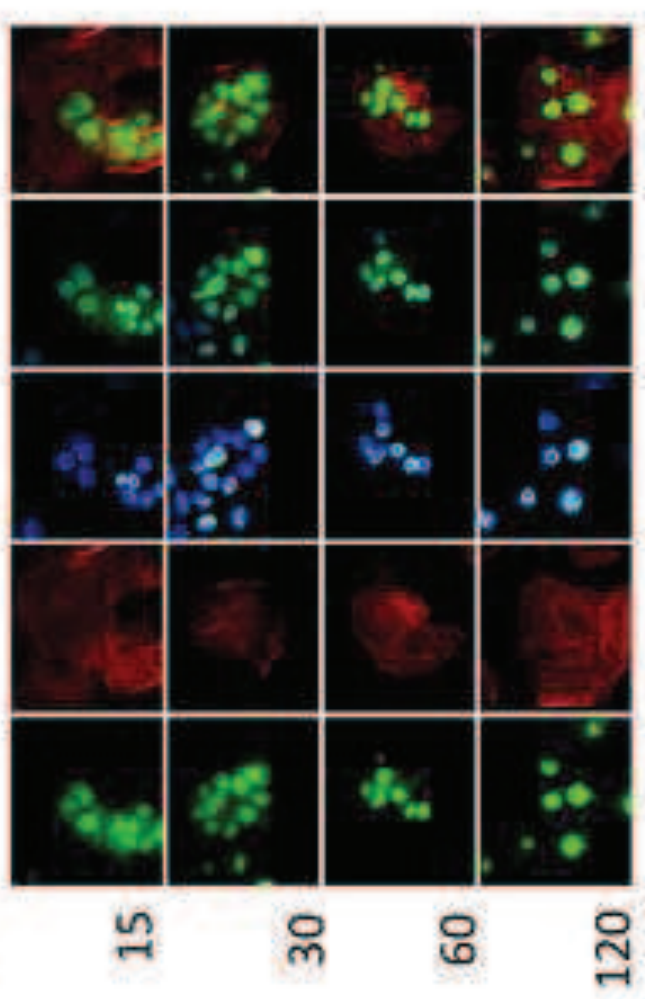

(wroot) $)^{2} \mathrm{O}^{2} \mathrm{H}$ 

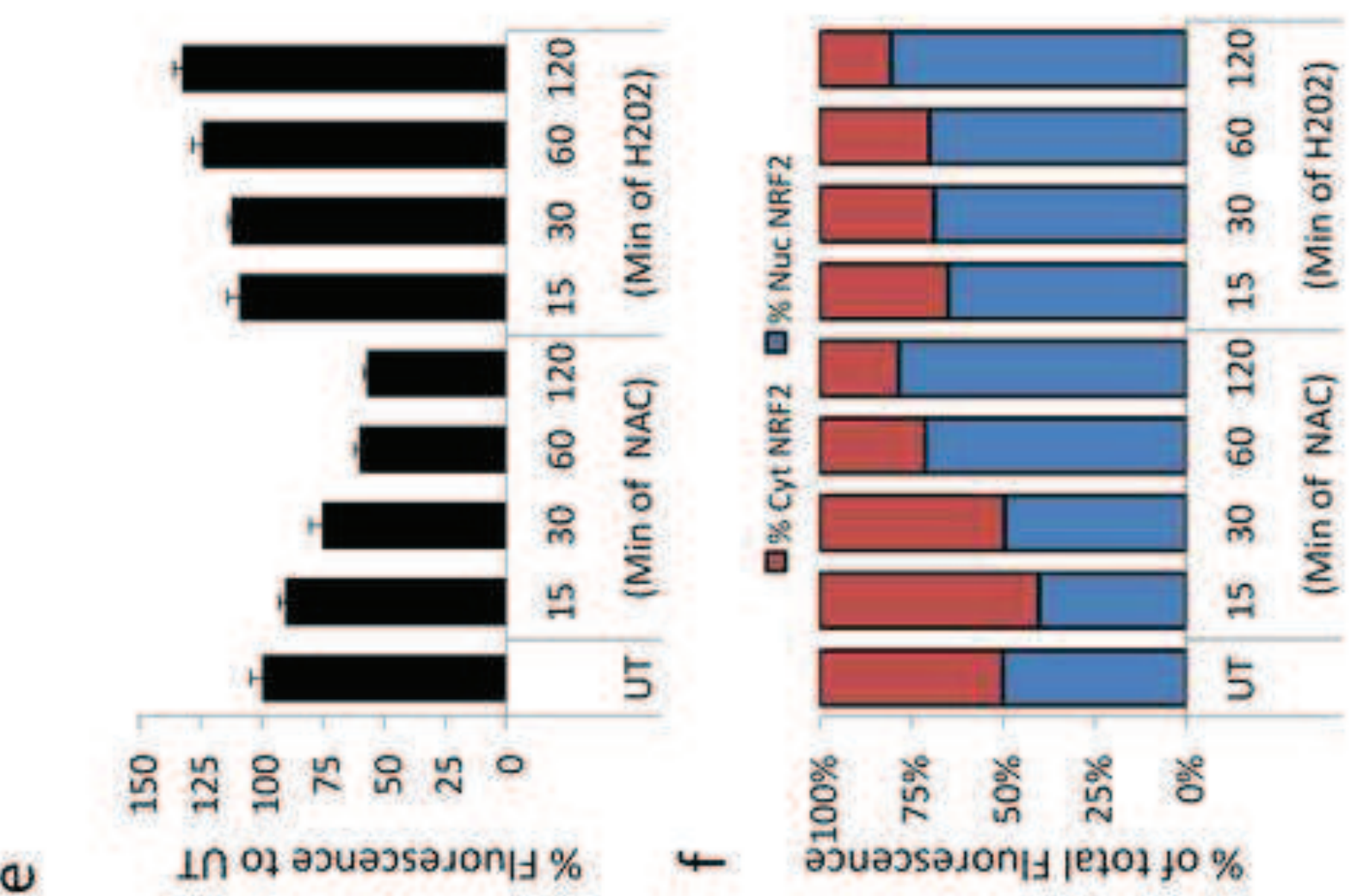

ठํㅇํ i

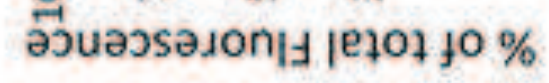
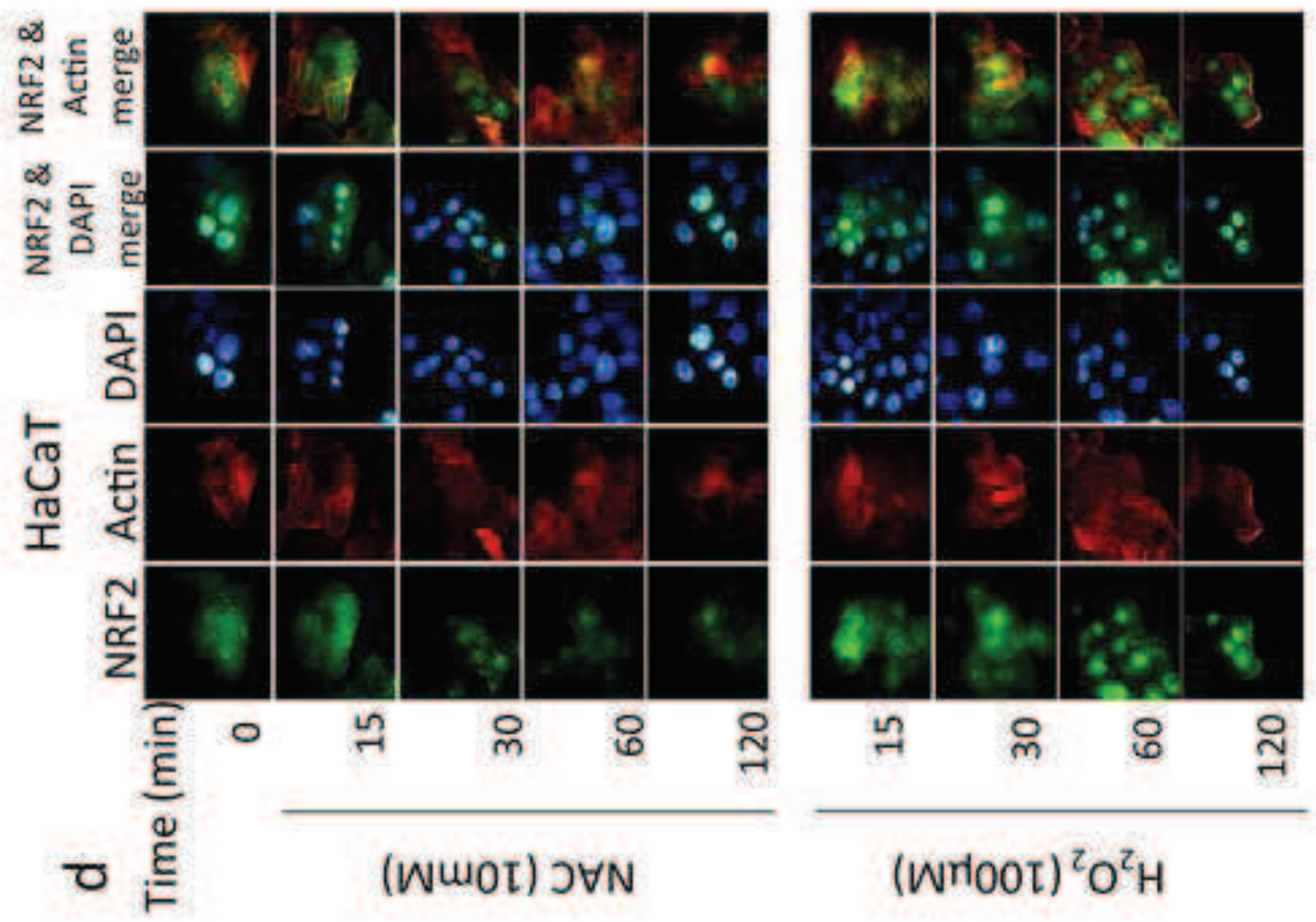

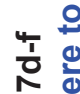

ఏ 은 


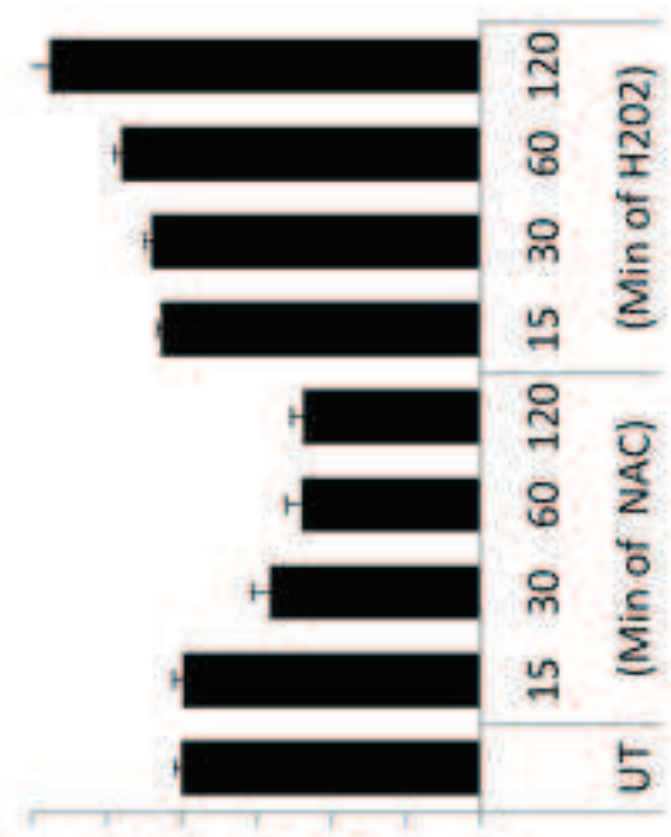

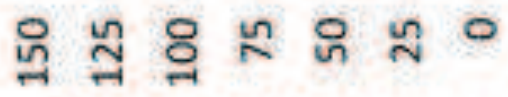

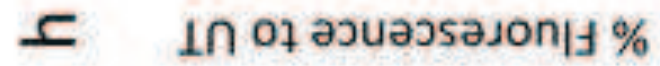

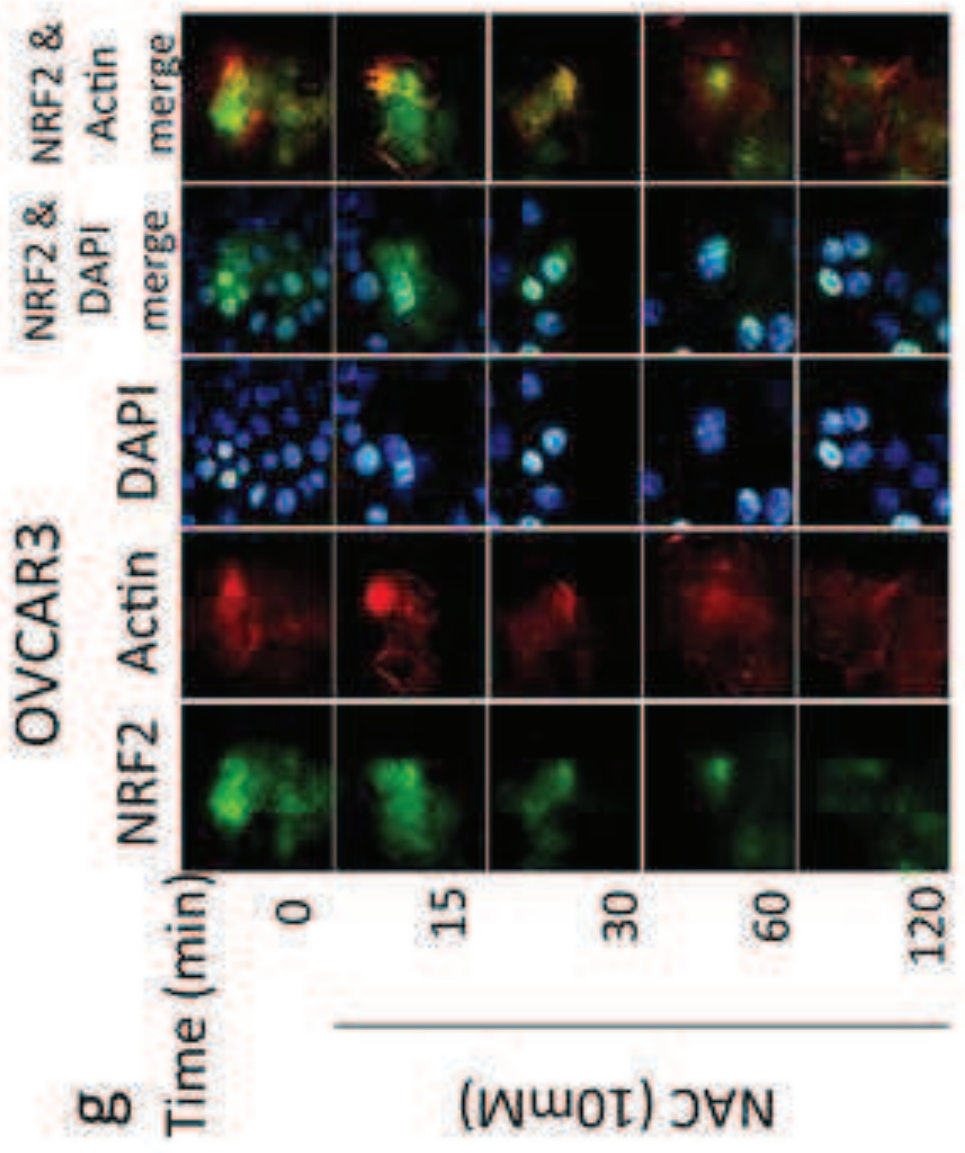

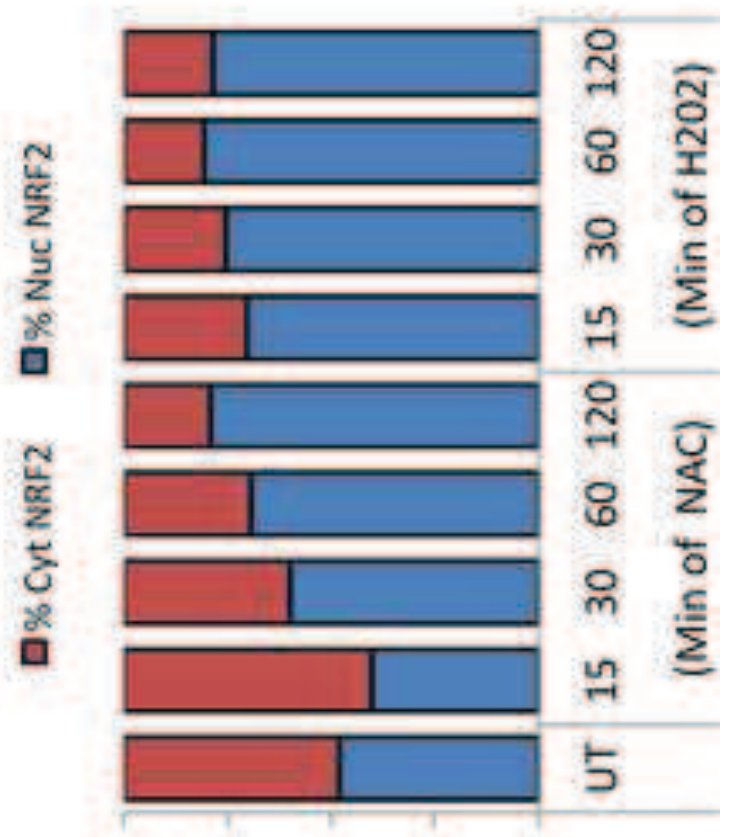

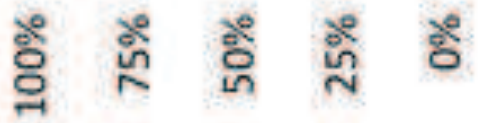

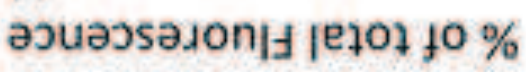

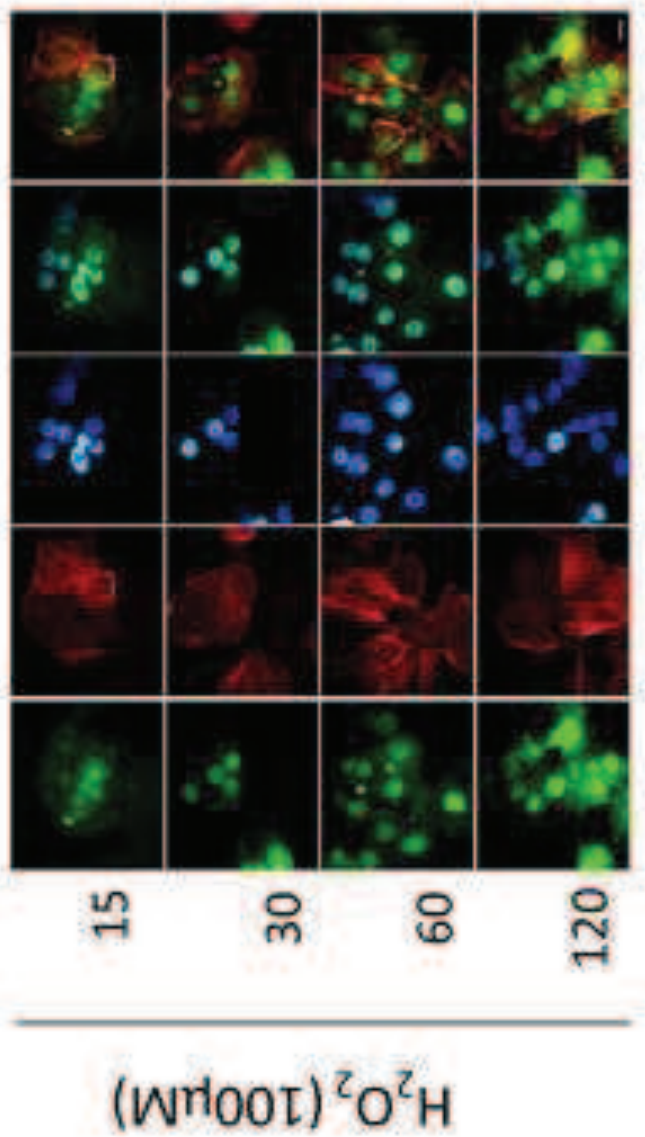

న⿱乛龰 


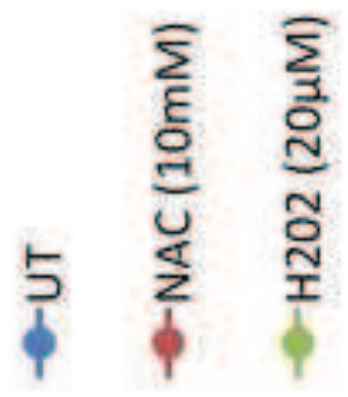

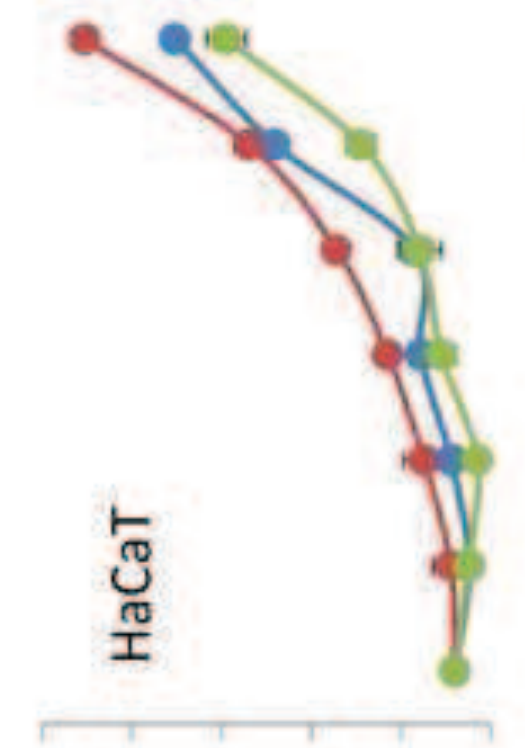

느슥을 n (.0T) Jaqunn IIaj $^{2}$

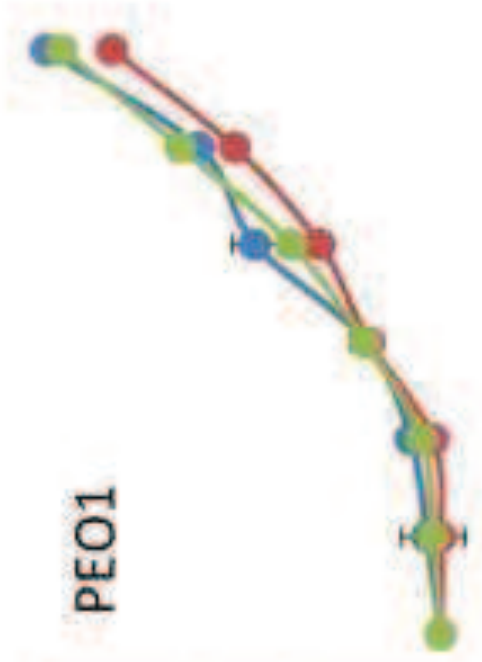

으윽 (,0I) daquinN ॥əว

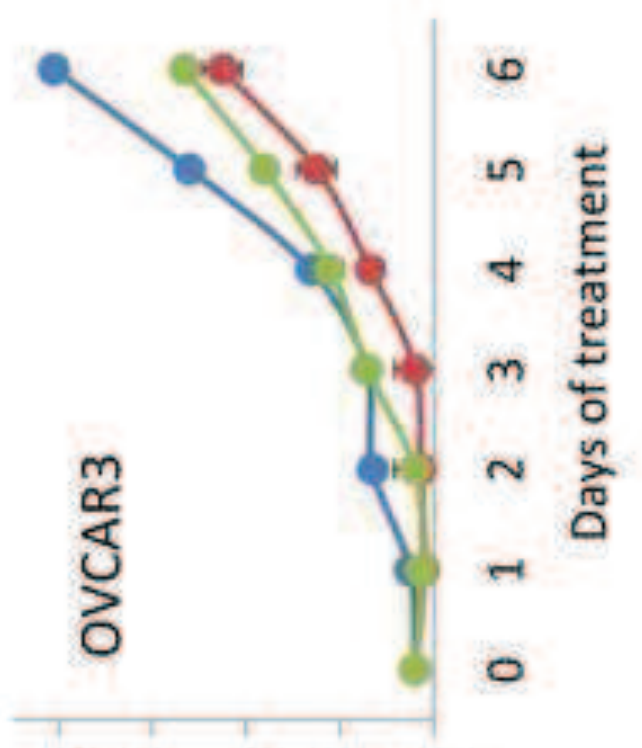

융ㅇㄱ응 (.0I) saqunN $\|$ ว

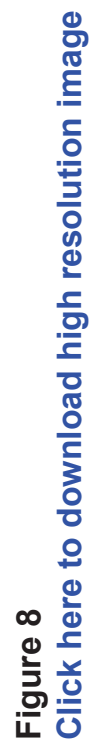




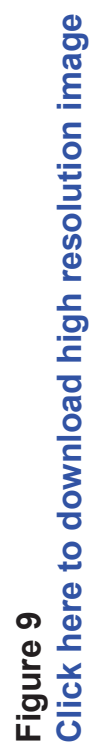

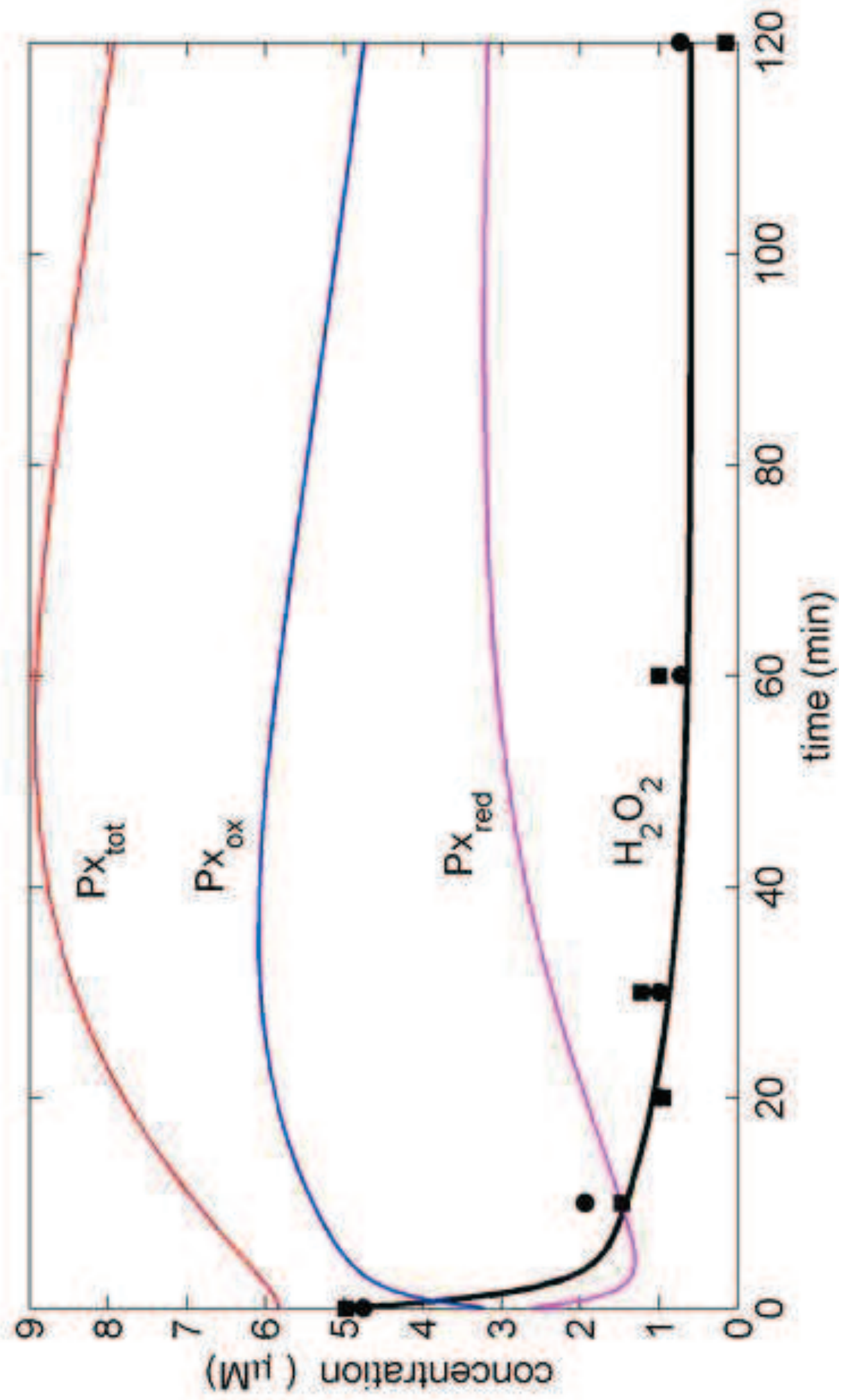




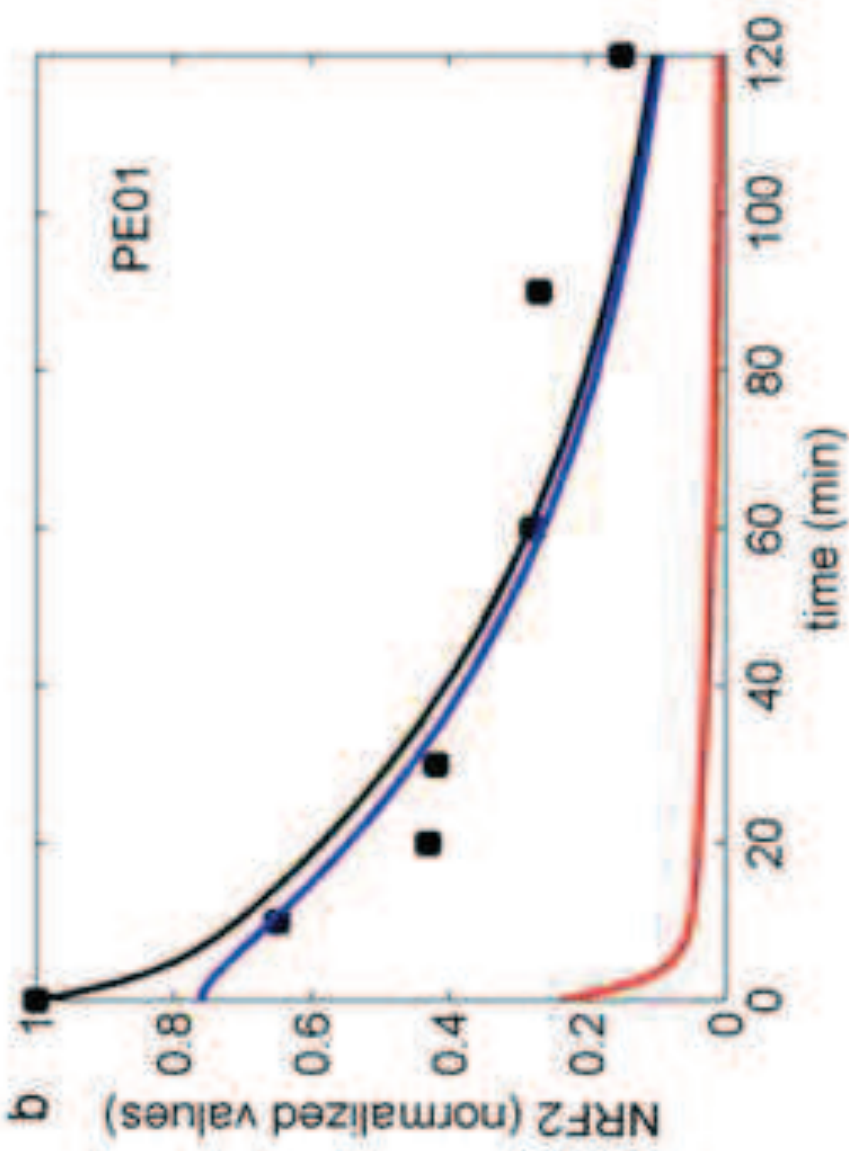

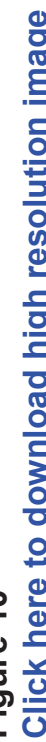

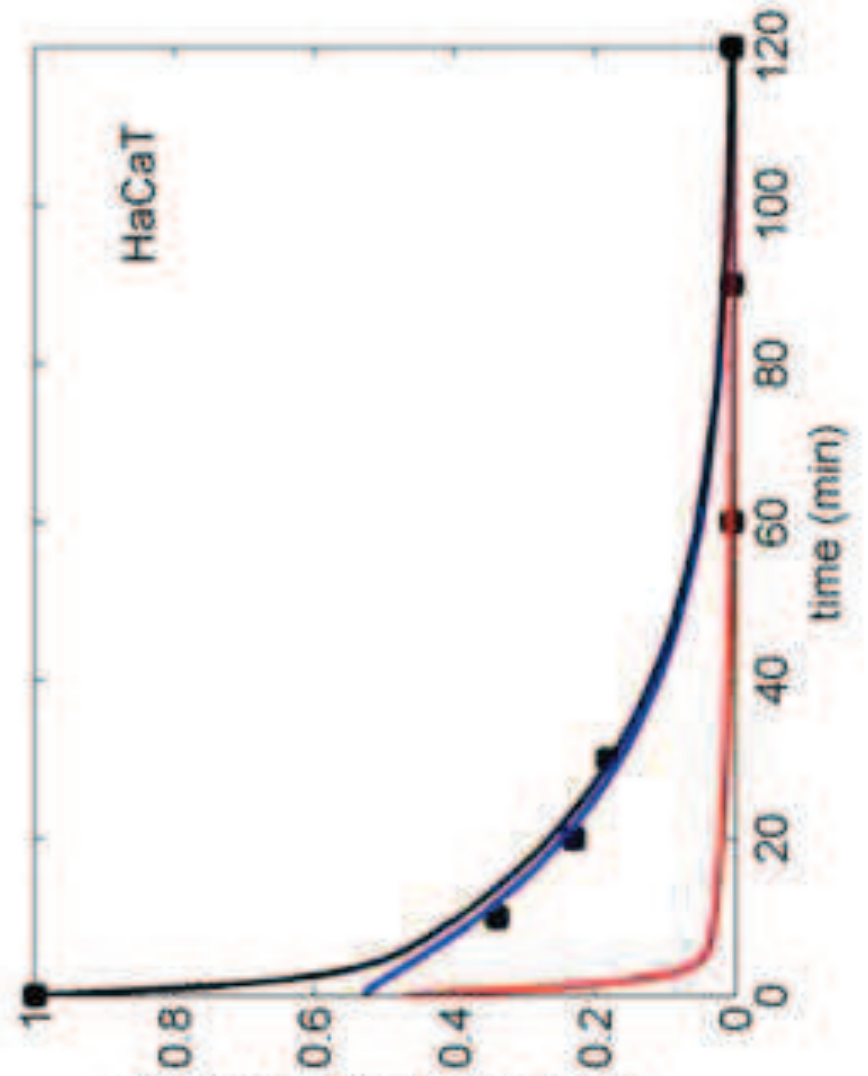

(c) (sanjex pazıeuuou) ZJaN 

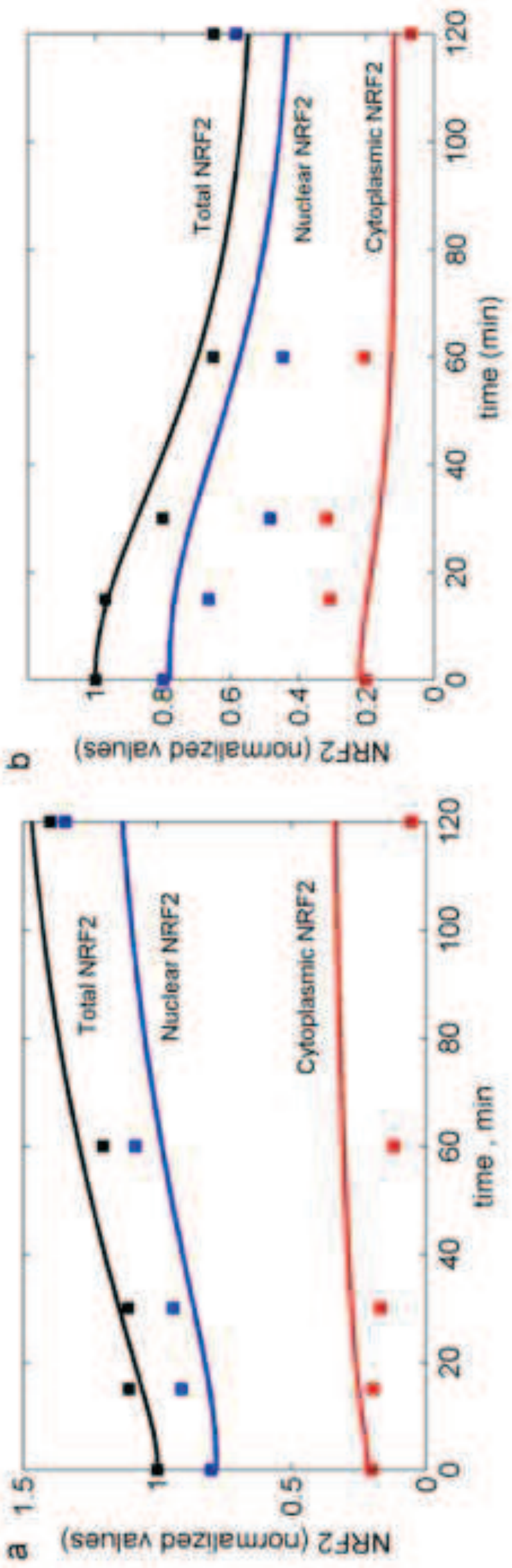

듕 


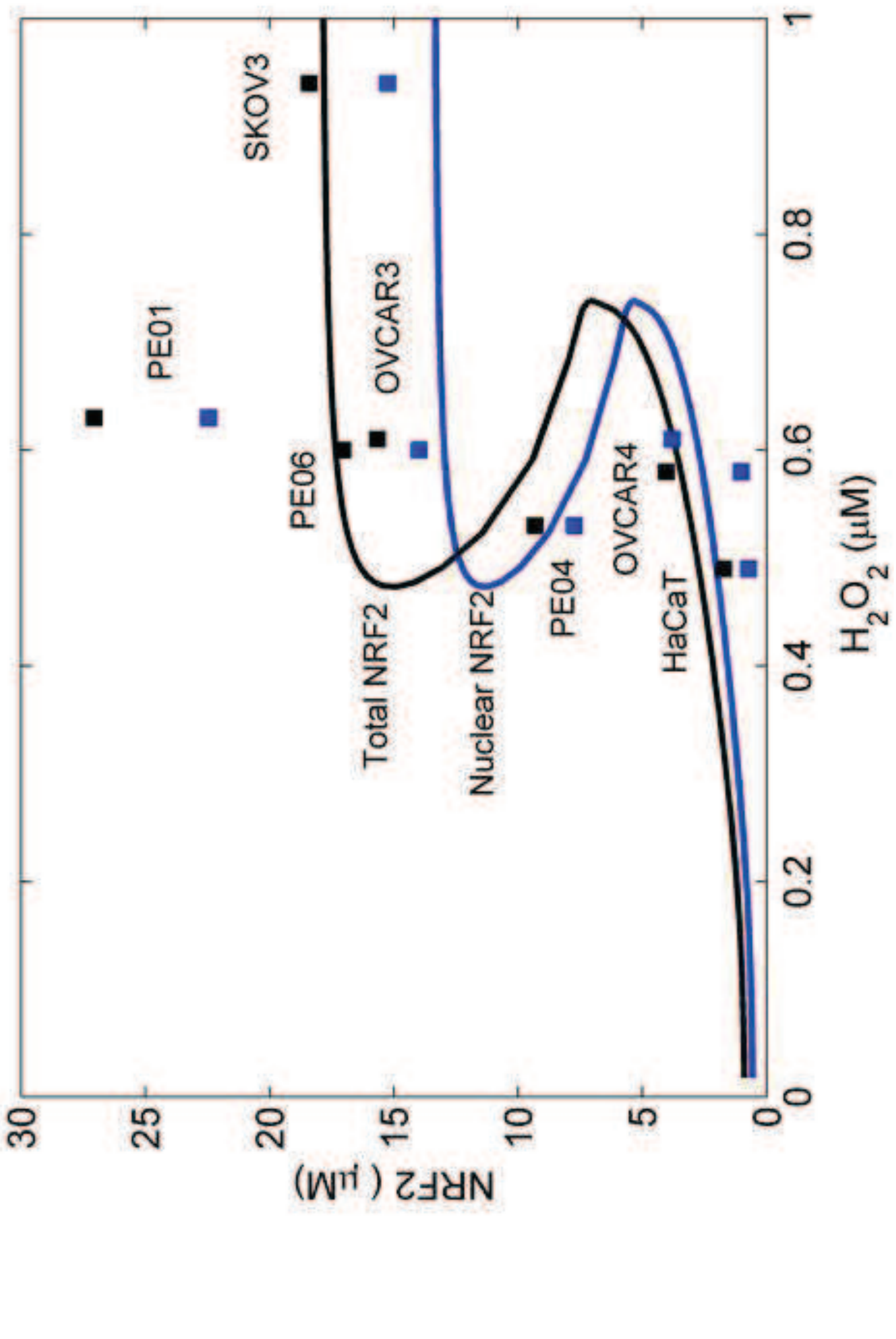


Click here to download Supplementary File: Supplement I.pdf 